\title{
Proyecto pedagógico de la Gran Cólombia: una ruptura frente a los ideales republicanos'
}

La Gran Colombia pedagogical project: A rupture with republican ideals

Fechà de recepción: 30 de marzo'de 2007. Fecha de aceptación: 13 de julio de 2007
Bárbara Yadira García Sánchez ${ }^{*}$

\section{RESUMEN}

Para ampliar la base letrada sobre la cual se construiría la ciudadanía en la Gran Colombia, era necesário aumentar sustancialmente la cobertura educativa en una sociedad donde los letrados eran escasos. Por ello fue necesario introducir el método de la enseñanza mutua o método lancasteriano. El proyecto pedagógico de la República fue esbozado en la medida en que el naciente Estado formulaba una política pública para el manejo de la educación y la instrucción, con miras a crear una nueva institucionalidad.

\section{Palabras clave}

Educación, proyecto pedagógico, escuela lancasteriana, Gran Colombia, república.

\section{ABSTRACT}

La Gran Colombia citizens have founded its basis at literacy education, demanding for knowing how to read and write as requirement to access on it. This condition was especially difficult for most of the population, who was

* Socióloga, Magíster en Sociología,-Doctora en Ciencias de la Educación. Profesora Facultad de Educación. Doctorado Interinstitucional en Educación, Universidad Distrital Francisco José de Caldas.

1 El preseı ti -rticulo se presentó como ponencia en el encuentro de Integración Latinoamericana organi/a'c l al la Universidad Distrital Francisco José de Caldas en noviembre de 2005. 
illiterate. The new project of nation needed to use an educational plan that offers the possibility to teach how to write and read, add and subtract to most of the people in the space of ten years. In order to achieve this goal, it was necessary to use the mutual teaching method or Lancasterian method, as an alternative for the diffusion of the first literacy and fundamental mathematics for they that had been relegated of educational institution during colonial period. In this way, Republic propose education for everyone as a mechanism that allows to create a new social order.

\section{Key words}

Education, Pedagogical Project, Lancasterian School, Gran Colombia, Republic.

\section{LA ESCUELA LANCASTERIANA Y EL MÉTODO DE ENSEÑANZA MUTUA}

Desde los comienzos de la Gran Colombia, se consideró la necesidad de construir un sistema educativo acorde con la nueva condición de la nación, que llegara a todos los ciudadanos y que fuese capaz de trasmitir el ideario republicano. De esta manera se tuvo en cuenta el método de enseñanza mutua como la alternativa que podría cumplir la expectativa planteada, pretendiendo una diferencia tajante respecto a los métodos utilizados en la educación colonial.

El método de la enseñanza mutua tuvo sus orígenes en el siglo xviı en la India. El misionero Andrew Bell comenzó su difusión, pero fue José Lancaster quien la redujo a sistema y la popularizó a partir de 1798 al abrir su primera escuela para niños pobres en Londres:

advirtiendo Lancaster que el número de educandos era superior a sus fuerzas, inventó un método de instrucción más simple y menos molesto que los comunes; y lo que es más importante de mayor economía. Dividió la escuela en clases colocando a la cabeza de cada una un joven de superior habilidad con el nombre de monitor y bajo la inmediata inspección del maestro, por cuyo medio conoció que un solo maestro puede dirigir una escuela de 500 y aún de 1000 niños con gran facilidad y orden ${ }^{2}$.

2 Lancaster, J., Origen y progresos del nuevo sistema de enseñanza mutua del señor Lancaster, Londres, s.f., p. 1 .

C. CENTRO DE INVESTIGACIONES Y DESARROLLO CIENTIFICO 
En 1813, Lancaster organizó en Inglaterra la Sociedad Escolar Inglesa y Extranjera con el apoyo del Rey Jorge in y el patrocinio del Duque de Kent con el interés de difundir el método; que para este momento contaba con 95 escuelas establecidas que impartían educación a 30.000 alumnos. En su intento de expandir el sistema a la enseñanza superior, el método fracasa, por lo cual es censurado por el clero anglicano y por Bell, lo que le hace tomar la decisión de viajar a América, en donde recibe especial apoyo de.Simón Bolívar. En el Nuevo Mundo popularizó el sistema en Colombia, Venezuela y Estados Unidos?.

Durante todo este proceso de implementación del método, Lancaster publicó diferentes títulos: Mejoramiento de la enseñanza, 1803; Carta sobre la manera de educar y corregir en ciudadanos útiles a los pobres de Irlanda, 1805; Voz de la justicia en la causa de diez mil niños pobres, 1807; Silabario para uso de las escuelas, 1808; Noticias sobre el progreso del sistema de José Lancaster en la educación de los niños, 1810; Informe sobre los progresos de José Lancaster desde 1798-1811 y Opresión y persecución en 18164. Después de la estadía en Venezuela -que no fue exitosa, pues recibió apoyo personal y oficial de Bolívar sin resultados a la vista- viajó al Canadá. Murió en Nueva York en 1838.

\section{FUNDAMENTOS DEL MÉTODO LANCASTERIANO}

José Lancaster inició su experiencia pedagógica en el Instituto dé Borogh Road, la cual se hizo notoria por el número de alumnos que manejaba. El duque de Bedford y lord Sommerville se convirtieron en protectores del método desde sus inicios; el duque se desempeñó como presidente de la sociedad que apoyaba este sistema educativo. Una vez que el Rey Jorge in conoció la naturaleza de este plan educativo y comprendió la importancia del método yla influencia que podría llegar a ejercer en la población más pobre en favor de la moral pública y la religión, decidió aprobarlo y apoyarlo económicamente expresando que "uno de mis más vehementes deseos es, que todo niño pobre

3 Amunategui Solor, D., El sistema de Lancaster en Chile y otros paises sudamericanos. Santiago de Chile Imprenta de Cervantes, 1895 p. 21.

4 Ibíd., p. 21. 
de mi reino se le enseñe a leer la Biblia"s. En adelante el Rey, la Reina, príncipes y princesas se hicieron suscriptores anuales de la sociedad para apoyar el denominado "método de enseñanza mutua". Hasta el fin de sus días el Rey Jorge III envió la suscripción al Instituto de Borogh Road.

No obstante el apoyo real al plan, se establecieron pocas escuelas antes de 1808 , momento en el cual el método recibió criticas tanto por ser muy liberal como extenso para la educación de los pobres. Los suscriptores se retiraron quedando sólo los aportes de la familia real y dejando a Lancaster en una situación de endeudamiento que amenazaba con el cierre de las escuelas. El señor José Fox ofreció 2000 libras de su propio peculio para el pago de las deudas más urgentes y se hizo fiador de las restantes con que se pudieron pagar con la ayuda de amigos y nuevos suscriptores. Los duques reales de Kent y Sussex fueron protectores activos y sostenedores del instituto. Personajes del Parlamento británico apoyaron siempre el método.

La Sociedad de Escuelas Británicas, cuya sede era el instituto, tenía como objetivo la formación de

las personas deseosas de promover la educación de los pobres en todas las partes del mundo... ofrece toda facilidad a los extranjeros que deseen aprender el plan y propagarlo en su propio país y mantiene un acopio de pizarras, lecciones y todo el tren de la escuela, para el abasto de las que han de montarse por este sistema. Cierto número de las personas que solicitan hacerse maestros y maestras son sostenidas por el instituto y están más inmediatamente bajo el patrocinio y la inspección de la comisión. Esta es la causa principal de los gastos. A otras las sostienen sus amigos y solo van a la escuela a aprender el plan 6 .

El plan de la Sociedad para las escuelas Británicas y Extranjeras estaba dirigido a la educación de la población más pobre de cualquier denominación religiosa, excluyendo creencias o catecismo de sectas particulares y basándose en las enseñanzas morales y religiosas de la versión original de la Biblia, la cual se

5 Lancaster, J., Manual del Sistema de Enseñanza mutua aplicado a las escuelas primarias, Bogotá, S.S. Fox, 1826, p. 4.

- Ibid., pp. 6-7 
utilizaba como texto de lectura. De esta manera se évitaba al choque por las creencias religiosas o el proselitismo de cuialquier secta, lo que afianzaba la confianza de los padres garantizando la asistencia de los niños a la escuela ${ }^{7}$.

Uno de los principales fundamentos contemplaba el respeto por las creencias religiosas de los padres de familia; dando un lugar importante a la función de la moral y a la asistencia al culto que se profesara. Así se evitaban contradicciones con las creencias religiosas practicadas en las familias y se inculcaba a los niños el respeto por el culto de los padres y de los otros, $+\cdots$

Educados en esta misma unión los niños cuyos padres profesan dife-. rentes creencias, naturalmente hacen esperar que sentirán estimación y respeto hacia los otros y desaparecerá así el efẹcto de aquella preocupación religiosa que, en tiempos pasados, ha causado tantos males. al mundo, y se unirán todos los miembros de la comunidad por los vínculos de la caridad cristiana ${ }^{8}$.

El principio de la educación universal de los pobres, adoptado por la Sociedad de Escuelas Británicas, contemplaba que "por su estado de dependencia, los pobres son objetos dignos de cuidado y de atención de las clases más elevadas de la comunidad". Se asumía como una responsabilidad de las clases altas, controlar o evitar la expansión de la ignorancia y los vicios; de allí el surgimiento de todo tipo de sociedades con miembros destacados de la sociedad que trabajaban por la educación de los menos favorecidos.

Las escuelas elementales que utilizaban este método instruían a los niños en los deberes morales y sociales, en el conocimiento de las sagradas escrituras, la formación de la virtud y la inculcación de hábitos a la subórdinación y al freno. Los informes de escuelas que adoptaron este plan estaban de acuerdo en considerar los buenos efectos de esta educación no solo en los niños, sino también en los padres de familia ${ }^{10}$.

\footnotetext{
7 , Ibíd., p. 8.

* Ibíd.

$9 \quad$ Ibid., pp. 8-9.

in Ibid., p. 9.
} 
La escuela elemental insistía en la formación de nuevos hábitos a los alumnos poniendo la mayor atención en el aseo. Se solicitaba a los padres de familia el esfuerzo de enviar sus hijos a la escuela con la mayor decencia posible por considerar que de esta manera se contribuía a la formación de nuevos sentimientos, a reformar el carácter y a elevar la estima de los niños que por su condición de pobreza e ignorancia eran ajenos a la adquisición de este tipo de hábitos.

El ideal de la enseñanza mutua que apoyaba la Sociedad de Escuelas Británicas era extender a la gran masa del pueblo la educación, para disminuir el crimen y, en asocio con los esfuerzos de la Sociedad Bíblica y el sistema de bancos de ahorro para los pobres, prestar un servicio a este tipo de población ${ }^{11}$.

Teniendo en cuenta la cantidad de maestros de diferentes partes del mundo que deseaban aprender este sistema, la comisión determinó publicar un manual con toda la información necesaria que contribuyera a la implementación del método en los diferentes países.

Igualmente consideraba que todas las escuelas que se formaran podían servir de modelo para el establecimiento de otras o para la formación de maestros y monitores escogidos entre los niños que manifestaron mayor aptitud. La comisión central de Borogh Road ofreció apoyo y asesoría para todas las personas interesadas en el avance de la educación en su país o en cualquier parte del mundo.

En el Manual del sistema de enseñanza mutua aplicado a las escuelas primarias, en el apéndice, se consignó todo lo relacionado para la formación de sociedades de escuelas, de manera que sirvieran de guía para su establecimiento en cualquier parte del mundo.

El objeto de la fundación de las escuelas lancasterianas contemplaba la educación de los niños de la clase trabajadora de cada ciudad y su vecindario para mejorar su moral y ofrecerles una educación más propia. Quien estuviese interesado en abrir escuelas con este mínimo interés debía adoptar el reglamento de la Sociedad de las Escuelas Británicas, que a la letra decía:

\footnotetext{
"Ibid., p. 10.
} 
A: que el plan de la sociedad de la escuela Británica y extranjera, en razón de sus principios liberales y de su grande sencillez y economía parece ser el mejor adaptable a este fin; B: que con la mira de promover los objetos importantes de esta reunión, se forme una sociedad y se denomine la sociedad ---- para la educación de los niños de la clase laboriosa del pueblo y el adelantamiento de su moral. C: Que los niños de toda clase laboriosa, o mecánica, que residen dentro de la ciudad de ---- y su vecindario, son los objetos más propios de esta institución ${ }^{12}$.

Con estas consideraciones, la sociedad debía órganizar el gobierno, los privilegios de los suscriptores y gobernadores. Los suscriptores aportaban una cuota determinada y a cambio podían tener un número de niños constantemente en la escuela. La edad en que se admitían los niños era desde los seis años.

Las dêcisiones de la Sociédad sé tomaban a través de lás juntas generales y especiales; las generales se celebraban una vez al año en al cual se leían los procedentes de la comisión, se aprobabán o se módificaban', se évaluaban los fóndos, el estado de las escuelas, los informes de los suscriptores y se tomaban las decisiones particulares.

Las juntas especiales eran convocadas por tres miembros de la comisión especificando el tema que debía tratare. Estaba prohibido a los miembros de la comisión recibir compénsáciones pecuniarias por cualquier servicio o trámite de la sociedad. La comisión nombraba al maestro de escuela y a los oficiales inferiores de la sociedad úna vez que esta decisión se aprobaba en la Junta General ${ }^{13}$. Tödo lo relacionadó con el funcionamiento de la escuela era controlado por la comisión: el cumplimiento de las funciones del maestro, la inscripción de los alumnos, los libros que debían leerse, los temas de las lecturas generales las cuales debían limitarse a la Sagrada Escritura, las lećciones del' silabário y los de aritmética.

El reglamento contemplaba el procedimiento para el ingreso de los niños a la escuela, los cuales debían ser recomendados por los suscriptores, especificando el nombre de los padres, el lugar de alojamiento, ocupación, salarios,

\footnotetext{
12 Ibíd., p. 112.

13 Ibid., p. 115.
} 
culto que profesaban y el nombre y edad del niño que ingresaría a la escuela. La lista de niños recomendados debía someterse a aprobación de la reunión mensual de la comisión. Los niños admitidos no debían tener ningún mal contagioso y sus padres debían comprometerse a enviarlos aseados, bien lavados y con el pelo corto y peinados ${ }^{14}$.

El horario contemplado para la permanencia en la escuela era de las nueve hasta las doce del día y de las dos a las cinco de la tarde, variando según la época y el clima. Como indicación especial se estipulaba la asistencia de los niños al culto todos los domingos de acuerdo con las prácticas religiosas de las familias.

Los inspectores eran miembros de la Sociedad que tenían a su cargo el cumplimiento del reglamento en cada una de las escuelas. Por tanto debían asistir dos veces por semana a la escuela y verificar el progreso de los niños en la instrucción, la asistencia a clases, la asistencia al culto, la presentación personal. Estas observaciones eran consignadas para presentar los informes en la junta mensual de la comisión ${ }^{15}$.

El maestro de la escuela debía llevar una relación de los niños que asistían al culto del domingo y de los que no lo hacían, para presentarla al inspector; éste, a su vez, reportaba a la reunión de la comisión.

La Sociedad debería estar vigilante en que todos los niños que tuviesen la edad de estudiar, estuviesen inscritos en la escuela y para ello se pedía a los inspectores y maestros de escuela adelantar un registro con el número de niños, su edad, su lugar de residencia, su vecindario y el nombre de los padres para abrir una suscripción y promover la educación de dicha población. Lo contemplado en el reglamento igualmente era aplicado tanto a las escuelas de niños como de niñas ${ }^{16}$.

\footnotetext{
14 Ibíd., p. 117.

15 Ibid., p. 118

is Ibid., p. 120.
} 


\section{EL MÉTODO EN.LA'ESCUELA LANCASTERIANA}

En las escuelas lancasterianas se había adoptado el método de la enseñanza simultánea o mutua, en la que los alumnos estudiaban de manera grupal: "A una señal que el maestro dảba con el pito o la campanilla, los alumnos pasaban de los semicírcúlos a las mesas, o sea de la lectura a la escritura. Era una disciplina verdaderamente militar" ${ }^{\prime \prime}$.

Todas las indicaciones estaban escritas en los reglamentos, los cuales debían seguirse con precisión. Estas escuelas fueron comparadas con ibuques ide guerra. La labor académica se organizaba a través de monitores generales, monitores especiales y monitores auxiliares. La organización escolar para la implementación del método contemplaba' los siguientes aspectos:

- Toda escuela se divide en clases de treinta y cuarenta niños cada una. "Los adelantamientos que hayan hecho los de la misma clase deben ser iguales.

- A cada una de estas clases se señalará un niño adelantado, para que hága las veces de instructor o monitor de ella.'Este tiene que instruir 'los niños de la clase $y$ hacer que guarden todos buen orden y que estén muy atentos a sus lecciones.

- En toda clase completa ha de haber tres ayudantes, que sean los tres niños más adelantados de la misma clase.

- Además de los maestros y ayudantes, el maestro señalará un niño adelantado y de mucho juicio para vigilar el cumplimiento, de los monitores y demás niños. Este se llamará monitor general. .

- Habrá siempre dos monitores para cada clase que han se servir un día sí y otro no. El maestro cuidárá mucho de los adelantamientos de los monitores. Se debe considerar monitor de ellos. Los que no están de servicio se formaran todos los días en una clase bajo su inmediata instrucción ${ }^{18}$.

Este funcionamiento de la escuela era igual para niños que para niñas; la diferencia estribaba en è amoblamiento del espacio físico, ya que para la escuela de niñas se requería otro tipo de aditamentos como gabinetes para guardar

17 Amunategui Solor, D., op. cit.

18 Lancaster J., op. cit., p. 1. 
mantillas y gorras, aguamaniles con jabón y toalla para el lavado de las manos. De resto el sistema de lectura, escritura y aritmética era igualmente aplicable a los niños y a niñas. El manejo del tiempo difería en las escuelas de niñas, ya que en ellas debía preverse el espacio distribuido para aprender a coser, bordar y otro tipo de labores específicas ${ }^{19}$. La formulación del método lancasteriano se apartaba de los postulados del método antiguo en sus fundamentos, reglas y prácticas.

\section{DIFUSIÓN DEL MÉTODO LANCASTERIANO}

La expansión del método lancasteriano se produjo en Londres, en 1808. De allá fue acogido con éxito en las principales ciudades y en otras partes del reino, donde se establecían maestros enviados por la escuela matriz de Londres. El éxito del método se reportaba especialmente "en los distritos fabricantes, donde la necesidad de brazos hacía que los niños solo pudieran dedicar poco tiempo a la escuela"20. El sistema fue muy bien acogido por la rapidez con que los alumnos adquirían la instrucción. La sociedad para promover la educación de los pobres en Irlanda con el patrocinio de los duques de Kent y Sussex, fue establecido en 1811. Dicha sociedad promocionó gran número de maestros y escuelas, las cuales ascendían a 107: eran 62 protestantes y 45 católicas $^{21}$. En mayo de 1814, en Escocia, se consolidó la Sociedad de Escuelas. Británicas y Extranjeras para apoyar el nuevo sistema con el método Lancaster.

Los reportes señalaban que hacia 1808 existían escuelas lancasterianas en Rusia, Alemania, Asia y África. Se llevó a los hijos pobres de militares y soldados que se encontraban en las fronteras librando batallas. Muchas veces fueron los mismos sargentos quienes hicieron las veces de maestros en estas escuelas ${ }^{22}$.

En 1819, el rey de España adopta el método lancasteriano, mediante la expedición de un decreto en el cual se establecía:

19 Anónimo. Manual para el método de enseñar la costura en las escuelas lancasterianas de niñas de la república del Perú, adoptado del que se usa en las escuelas elementales de Inglaterra. Lima; Imp. de la Instrucción Primaria, 1827, p. 3.

20 Lancaster, J., s.f., op. cit., p. 3.

21 Ibíd., p. 5.

22 Ibid., p. 6. 
Tengo la satisfacción de poner en sus manos una copia de un real decreto, que autoriza el establecimiento de las escuelas bajo el sistema lancasteriano en todo el reino y tengo razón para esperar que será adoptado en todas las ciudades, villas y lugares del reino, como que muchos vienen ya a nuestra escuela central que se abrió en mayo ultimo y en la que se han educado 320 niños... aprovecho esta oportunidad para asegurar a los miembros de la sociedad inglesa de mi sincero agradecimiento por el honor que han tenido la bondad de conferirme, eligiéndome miembro honorario de esta caritativa y patriótica institución ${ }^{23}$.

De acuerdo con los informes de la sociedad lancasteriana de Londres, para el año de 1819, se habían establecido escuelas en todos los países de Europa, excepto Portugal ${ }^{24}$.

En Francia, el método se difúnde en laś cárceles, y éntre los militares, los pobres, los hospicios y las clases industriosas. En un extracto del Diario de la Educación, 'en 1819, sé informaba que se había organizado una escuela dirigida a los criminales en la prisión de Montaigne, cuyos resultados eran muy favorables:

El orden, la disciplina y el aprovechamiento moral se demuestran evidentemente. En suma, el aspecto de la prisión ha cambiado enteramente, $y$ los juegos indecentes, y las conversaciones escandalosas ya no existen: todo es orden, ocupación y sumisión. ¿Hay un objeto más benéfico que el de restituir à la sociedad aquellos criminales a quienes el vicio había separado de ella? Se sigue de aquí que el castigo no es ya el acto de justicia, y de la prudencia, sino que se requiere para su corrección, la filantropía, y la benevolencia ${ }^{25}$.

En Francia se adopta el método en 1815 con el nombre de Núvo Sistema de Educación por el conde Lasteyrie, y se promovieron las escuelas elementales, en todo el territorio, bajo el titulo de Sociedad para la Instrucción Elemental.

\footnotetext{
23 Ibíd., p. 13.

24 Ibíd., p. 9- 10.

25 Ibíd., p. 12.
} 
La primera escuela en París se abrió en junio de 1815, tanto para católicos como para protestantes. El rey apoyó la causa donando 50.000 francos anuales para su mantenimiento. En 1818 existían 900 escuelas lancasterianas en Francia.

La difusión del método lancasteriano en América empezó en Nueva York en 1806 mediante la formación de las sociedades y la apertura de escuelas donde se inscribieron 2000 niños de ambos sexos. Con este medio de instrucción, el condado de Filadelfia disminuyó sus gastos en educación de 37.104 pesos a 9.276. En las Indias Occidentales, como Haití, se crearon escuelas elementales en enero de 1817. El Rey se refería así a la educación: "La instrucción pública es el más seguro medio para mejorar las costumbres de una nación y formar el carácter"26.

En Chile también se hacían elogios al método:

Según se lee en la Gaceta Ministerial de Chile del 22 de septiembre de 1821, ¡la fundación de un colegio servía así para conmemorar la gloriosa fecha del nacimiento de la patria! Los gobernantes de entonces creyeron que la mejor manera de arraigar en nuestro suelo la enseñanza mutua era injertarla en el árbol poderoso y robusto del Instituto Nacional ${ }^{27}$.

La primera escuela con este método se llamó Escuela central de enseñanza mutua según el sistema de Lancaster, y se constituyó en el primer esfuerzo a favor de la educación popular, laica y gratuita.

Hasta 1821 existian en Chile ocho escuelas lancasterianas sostenidas por el gobierno. Diego Thomson, su fundador, llevó su obra a Buenos Aires, Montevideo, Lima y Bogotá. Las escuelas de las ciudades y provincias se organizaron a través de una "sociedad escolar"; se establecieron escuelas de niños y algunas de niñas.

\footnotetext{
26 Ibíd., p. 8 .

27 Amunategui Solor, D., op. cit., p. 78.
} 
Chile fue uno de los primeros países en Suramérica que adoptó el método lancasteriano. Luego se abrieron las de Perú. En Brasil se abrieron por decreto de 1 de marzo de 1823; en México, en 182228.

Las principales críticas al método lancasteriano en Chile provenían de fanatismo religioso. Uno de los adversarios del método expresaba "que se me cite un solo enemigo de la religión y de la monarquía que no sea un partidario fanático de la enseñanza mutua y dejaré de pedir la supresión de ella". Tanto en Chile como en Francia el método despertó controversias y fue alimentado por la desconfianza de las, nuevas ideas.

\section{ESTABLECIMIENTO DEL MÉTODO LANCASTERIANO EN COLOMBIA}

Las reformas educativas del Congreso de Cúcuta consideraron la necesidad de establecer un método uniforme en todo el territorio nacional. El artículo 14 dé la lev 15 de 1821 decía textualmente:

El método de enseñanza será uniforme en todo'el territorio de la Repú- blica, para lograrlo, el poder ejecutivo hará los reglamentos necesarios para el gobierno y economía interior de las escuelas, estableciendo en ellos premios y certámenes los cuales reglamentos presentará al próximo congreso para su aprobación y reforma; igualmente mandará

- componer e imprimir todas las cartillas, libros e instrucciones necesarias para la uniformidad y perfección de las escuelas ${ }^{29}$.

En el artículo 15 de la misma ley se autorizaba al poder ejecutivo para que mandara establecer en las primeras ciudades de Colombia escuelas normales del método lancasteriano o de enseñanza mutua, para que de allí se difundieran a todas las provincias. Su financiación estaría a cargo de los fondos públicos, dando cuenta al Congreso.

El método lancasteriano es introducido en Colombia por fray Sebastián Mora, de la orden franciscana, quien lo había aprendido en España, a donde fue

28 Ibíd., p. 25.

29 Ley 15 del 6 de agosto de 1821 , sobre el establecimiento de escuelas de primeras letras para los niños de ambos sexos. En Codificación Nacional, Imprenta Nacional; :1924, tomo 1, p. 29. 
deportado por su participación en las luchas revolucionarias. A su regreso a Colombia, en 1820, fundo una escuela en la localidad de Capacho, Venezuela. Santander lo invitó a Bogotá con el fin de que abriese una escuela lancasteriana en la Nueva Granada, convirtiéndose así en la "primera de las tres escuelas normales" del método lancasteriano que Santander ordenó fundar en Bogotá, Caracas y Quito. Cada una de estas normales debía recibir por lo menos un estudiante de las provincias vecinas, quien aprendería la nueva técnica y luego la llevaría a su provincia" ${ }^{30}$, para difundirlo por todo el territorio nacional.

La fascinación que causo el método en Colombia hacia referencia a la rapidez con que los niños eran instruidos: "Inmediatamente después pusieron los niños en practica el método en que se han instruido perfectamente en menos de veinte días; los maestros de los cantones estaban de espectadores y continuaban aprendiendo"31.

Algunas de las escuelas abiertas en 1823 tuvieron en cuenta todos los requerimientos que el reglamento exigía: "Tenéis a la vista una sala espaciosa con todos los útiles necesarios para montar una escuela según el plan del ilustre Lancaster. Ningún gasto se ha omitido, todo esta cómodo, decente, arreglado y digno si puedo decirlo de las intenciones del gobierno"32.

El método de enseñanza mutua encontró gran acogida en Colombia. Los certámenes públicos en donde se daba cuenta a los padres de familia, al gobierno y a los vecinos en general del aprovechamiento de los niños eran motivo de celebración en villas y ciudades:

En 1823 la sola provincia de Bogotá se vanagloriaba de tener quince escuelas primarias lancasterianas; hacia 1827 el secretario del interior declaró que en el conjunto del país existían 52 escuelas lancasterianas y 434 escuelas primarias del viejo estilo con un total de 20.000 asistentes $^{33}$.

30 Bushnell, D. El régimen de Santander en la Gran Colombia, Bogotá, Tercer Mundo Editores y Universidad Nacional de Colombia, 1966, p. 213.

31 Escuelas, en El Eco de Antioquia, 26 de enero de 1823, $n^{\circ}$. 36, p. 148:

32 Señores, en El Correo de Bogotá, Bogotá, 13 de marzo de 1823, nº. 189, p. 657.

33 Gaceta de Colombia, agosto 3 de 1823; El Constitucional, junio 24 de 1824 y julio 19 de 1827. Citado por BUSHNELL, D., op. cit., p. 215. 
Aunque ıa aırusion del método lancasteriano encontró diversos obstáculos, sobre todo en la falta de fondos para su establecimiento y sostenimiento $y$ la ausencia de maestros preparados, significó un aporte importante en la ampliación de la población escolarizada entre 1820 y 1837.

Durante las decadas de los años veintes y treintas; el sistema de educación mutua fue considerado como la clave para una rápida expansión educativa. En 1827 el $10.7 \%$ de la totalidad de las escuelas primarias el $18 \%$ de los estudiantes habían adoptado el método lancasteriano; en 1835 el $18.8 \%$ de las escuelas y el $34.5 \%$ de los estudiantes utilizaba el sistema. Mediante el empleo del método lancasteriano y de instrucción convencional, el gobiérno lógró, hasta 1837, un progreso sustancial en la difusión de la educación primaria, partiendó de la inšignificante base del periodo colonial, en 1837 las inscripciones primarias habían alcanzado un numero superior a los 25.000 estudiantes, aproximadamente el $1.4 \%$ de la población nacional y ún $8.7 \%$ 'de la población eń edad escolar ${ }^{34}$.

Las ventajas del método lancasteriano estaban a la vista.

\section{VENTAJAS DEL MÉTODO LANCASTERIANO}

Entre las ventajas más relevantes del método lancasteriano, reportadas por los diferentes países donde fue aplicado, se señalan la propagación de las escuelas de instrucción primaria a muy bajo costo y con un reducido número de maestros ya que se necesitaba solo uno por establecimiento; desplazamiento del método tradicional por el sistema de enseñanza mutua; adopción del sistema por las asociacionés religiosas en sus escuelas; disminución del usó de castigo corporal, ya que él sistema lancasteriano lo prohibía ${ }^{35}$.

En Colombia, el método fue aceptado con algunos reparos. De diferentes regiones del país reportaban sus ventajas durante los primeros diez años de su aplicación. La provincia de Antioquia, en 1823, manifestaba que el método

${ }^{4}$ Safford, F., El ideal de lo práctico, Bogotá', Universidảd Näcional de Colombia, Áncora Editores, 1989, p. 81.

35 Amunategui Solor, D., op. cit., p. 28. 
de enseñanza mutua sentaba las bases del edificio de la instrucción pública y que se convertía en un poderoso estimulo para la formación de los ciudadanos $^{36}$. Un elemento positivo era la prontitud con que los niños aprendían "sin causarles el fastidio y la aversión, efectos necesarios del modo bárbaro con que se han enseñado hasta ahora, multiplicando el trabajo y disipando el más precioso tiempo de la vida" ${ }^{37}$.

Teniendo en cuenta la necesidad del país de avanzar rápidamente en la instrucción pública generalizada, el método lancasteriano se presentaba como la herramienta más adecuada para su cumplimiento, ya que un solo maestro atendería un número elevado de niños. Ante la carencia de maestros y de espacios físicos donde funcionaran las escuelas, este método se convertía en el ideal.

Con respecto a lo países, nuevos, en que es necesario que a paso igual las ideas políticas y las morales, la instrucción del hombre y la del ciudadano, el método de Lancaster tiene prerrogativas de la mayor importancia. Si se considera que un buen maestro basta para una escuela de 300 o más discípulos, y que entre estos es casi imposible que no descuellen muchos, llegando a ser capaces de dirigir otras tantas escuelas, se conocerá el incalculable beneficio que resultara de su admisión en unos pueblos que todavía gimen bajo el peso de las consecuencias de la tiranía a que han estado sujetos ${ }^{38}$.

El método fue aplicado con éxito en las escuelas de primeras letras, "exceptuando la parte superior de ella que requiere un ejercicio libre de la razón, un tino que solo puede ser efecto del gusto, o una excelencia de que todos los individuos no pueden participar de igual grado"39. De hecho, el éxito en los demás países donde fue adoptado se logró en su aplicación en la escuela primaria, pero en el momento en que se pretendió generalizar a la educación superior fracasó y Lancaster tuvo que abandonar su país. Aún así, el método tuvo aceptación

\footnotetext{
36 Al Excmo. Sr. Francisco de Paula Santander, Vicepresidente de la República de Colombia, en Gaceta de Colombia, Bogota, 16 de septiembre de 1827, $\mathrm{n}^{\circ} .309$, p. 3.

37 Discurso del preceptor, en El Eco de Antioquia. 26 de enero de 1823, nº. 36, p. 149.

38 Método de enseñanza mutua, El Conductor, Bogotá: del 6 de febrero de 1827, nº 2, p. 7.

39 Ibíd., p. 8.
} 
en muchas naciones civilizadas, recibiendo el apoyo de diferentes gobiernos y sociedades que trabajaron para extenderlo por diferentes países del mundo ${ }^{40}$.

El argumento que se esgrimía en la Gran Colombia, hacia 1827, en defensa del método era que si tan importantes gobiernos y meritorios personas del mundo lo habían apoyado, ¿porque en nuestro país se tendría que estar en contradicción con él? “ ¿No son sus brillantes resultados lo que han multiplicado a su favor estas asociaciones? ¿ No será deshonra para Colombia que ella sola deprimiese, lo que sin contradicción se halla aplaudido en las ciudades más cultas de Europa? ${ }^{41}$

Aunque el método antiguo se continuó utilizando claramente hasta 1834, se puede evidenciar que el método lancasteriano alcanzó a ser mayormente utilizado en las provincias de Bogota y Antioquia posiblemente por las ven' tajas geográficas del territorio y porque por su condición de centros políticos importantes manejaban recursos económicos que facilitaron la apertura de escuelas con este método ${ }^{42}$.

Las ventajas del método se reconocían en cuanto a la facilidad que representaba la formación de nuevos sujetos que debían alcanzar el estatus de ciudadanía mediante el aprendizaje de la lectura y escritura. El reto de la nueva nación se había propuesto alcanzar el mayor número de ciudadanos que supiesen leer y escribir para 1830, momento en el cual se revisaría la Constitución de 1821; lo que necesitaba el Estado eran buenos ciudadanos y estos no brotaban por naturaleza, sino que se formaban por la buena educación que lograría desterrar la ignorancia generada en la Colonia ${ }^{43}$. El método lancasteriano, por ejecutarse de manera acelerada, facilitaba el logro de esta meta.

Uno de los principios metodológicos que mayor impronta producía, tanto a los padres de familia como al gobierno, radicaba en el logro aparente fácil y rápido de la disciplina, columna vertebral del éxito de cualquier método

\footnotetext{
40 Ibíd., p. 63.

41 Ibid., p. 64.

42 Al Excmo. Sr. Francisco de Paula Santander, Vicepresidente de la República de Colombia, en Gaceta de Colombia, Bogota, 16 de septiembre de 1827, n*309, p. 3.

43 Discurso del preceptor, en El Eco de Antioquia. Ref. cit.
} 
pedagógico familiar o escolar: "el silencio y el buen orden, y la uniformidad, contribuyen no poco al feliz y breve adelantamiento de los niños y el maestro". El requerimiento disciplinar para el éxito de este método era altísimo; todo estaba diseñado para trabajar en absoluto silencio, en tiempos muy precisos y con órdenes muy concretas, que no aceptaban ningún tipo de distractores. Este método era lo más cercano a la producción fabril o al funcionamiento de la milicia.

Otro elemento considerado ventajoso era que el método requería diferentes tipos de monitores para su implementación, pues ello significaba una oportunidad de aprendizaje de los niños que desempeñaban este rol, porque al enviar a otros se instruían al mismo tiempo. De ello se desprendía la facilidad con que los estudiantes adquirían hábitos de orden, regularidad y disciplina: "inspirando el amor al trabajo y la afición al estudio y acostumbrando desde temprano a la alternativa de mando y de obediencia, de superioridad y de subordinación, de que después se hacen tantas aplicaciones en todas las transiciones y épocas de la vida" ${ }^{34}$.

Durante el periodo se consideraba que la excelencia del método radicaba un que éste era puramente maquinal:

en la niñez es tan fácil someterse a una rutina metódica y habitual, como difícil hacer grandes esfuerzos de inteligencia y de aplicación. Es necesario proporcionar las adquisiciones a las facultades, y no colocar el objeto que se va conseguir más allá del alcance del individuo. Mientras más insensible es el progreso, más seguro y menos repugna y desanima la tarea ${ }^{45}$.

Esta concepción del método como puramente maquinal concuerda con las ideas que se tenían de la infancia esta época la cual se consideraba una etapa en que la niñez se asimilaba a unas tiernas plantas, que había que ayudar a enderezar o moldear a quienes no se les adjudicaba propiedades de raciocinio, comprensión e inteligencia, sino mecanización y memorización, que se adquirían a través de un progreso insensible.

\footnotetext{
44 Método de enseñanza mutua.

45 Ibíd.
} 
Las ventajas más relevantes del método son descritas de forma general por José María Triana ${ }^{46}$ de la siguiente manera:

\begin{tabular}{|c|c|}
\hline Método antiguo & Método lancasteriano \\
\hline 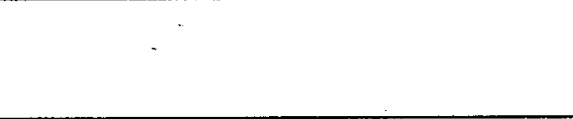 & $\begin{array}{l}\text { Los niños se ocupan de continuo sin } \\
\text { fatigarse pues se varían agradablemente } \\
\text { los trabajos. }\end{array}$ \\
\hline & $\begin{array}{l}\text { Los progresos en la escritura son seis } \\
\text { veces mayores }\end{array}$ \\
\hline $\begin{array}{l}\text { En el antiguo método se necesitaban } \\
\text { tantos libros, cuantos niños había en la } \\
\text { escuela. }\end{array}$ & $\begin{array}{l}\text { y ahora basta uno para toda ella aun } \\
\text { cuando sea de mil niños. }\end{array}$ \\
\hline $\begin{array}{l}\text { En el antiguo método, de } 50 \text { niños, } \\
49 \text { estaban ociosos durante la lectura. } \\
\text { Fingian mirar el libro, y se entretenían } \\
\text { en cualquier otra cosa a pesar de las } \\
\text { amenazas y los castigos. }\end{array}$ & $\begin{array}{l}\text { Más ahora todos leen una noble } \\
\text { emulación los anima y no pierden ún } \\
\text { solo instante. }\end{array}$ \\
\hline $\begin{array}{l}\text { En la escritura se les daban muestras que } \\
\text { se esforzaban a copiar, pero no siendo } \\
\text { inspeccionadas, sino rara vez, lo hacían } \\
\text { con lentitud y negligencia. }\end{array}$ & $\begin{array}{l}\text { Al presente son inspeccionados cada seis } \\
\text { palabras o silabas que escriben. }\end{array}$ \\
\hline $\begin{array}{l}\text { Antes los niños adquirían una escritura } \\
\text { desigual y siempre mala. }\end{array}$ & Hoy es elegante y casi igual en todos. \\
\hline $\begin{array}{l}\text { Era necesario que el maestro cortase las } \\
\text { plumas a cada instante. }\end{array}$ & $\begin{array}{l}\text { Hoy en día cada niño puede afilar su } \\
\text { lápiz. }\end{array}$ \\
\hline $\begin{array}{l}\text { En las antiguas escuelas, el perezoso } \\
\text { detenía los progresos a los demás, o el } \\
\text { maestro se hallaba en la necesidad de } \\
\text { darle diferentes lecciones. }\end{array}$ & $\begin{array}{l}\text { En las nuevas escuelas a cada instante } \\
\text { halla su nivel en la clase que es'capaz de } \\
\text { desempeñar. }\end{array}$ \\
\hline $\begin{array}{l}\text { Por el antiguo método, un niño después } \\
\text { de haber pasado dos o tres años en } \\
\text { aprender a leer, se dejaba entregado a si } \\
\text { mismo para escribir. }\end{array}$ & $\begin{array}{l}\text { Por el nuevo él escribe rápidamente } \\
\text { lo que lee, porque su escritura es un } \\
\text { deletreo mental de lo que le dicta su } \\
\text { monitor: de manera que en día deletrea } \\
\text { en su pizarra de } 156 \text { a } 160 \text { palabras } \\
\text { independientes de la lectura. } \\
\end{array}$ \\
\hline $\begin{array}{l}\text { Los maestros se esforzaban y eran } \\
\text { victimas de su celo. }\end{array}$ & Ahora trabajan sin hablar, \\
\hline $\begin{array}{l}\text { La ociosidad y la pereza no podían ser } \\
\text { remediadas por el antiguo método. }\end{array}$ & Por el nuevo no son tolerables. \\
\hline $\begin{array}{l}\text { Antes no se obtenía el silencio, sino a } \\
\text { fuerza de golpes y terror. }\end{array}$ & $\begin{array}{l}\text { Y al presente lo es por el orden de las } \\
\text { cosas, sea para oír lo que se dice, sea } \\
\text { para oír el dictado, sea para leer a su vez, } \\
\text { corregir al primero, y ocupar su lugar }\end{array}$ \\
\hline
\end{tabular}

46 Enseñanza mutua, El Conductor, Bogotá, 27 de marzo de 1827, nº 16, pp. 63 - 64. 


\begin{tabular}{|l|l|}
\hline \multicolumn{1}{|c|}{ Método antiguo } & \multicolumn{1}{c|}{ Método lancasteriano } \\
\hline $\begin{array}{l}\text { No se podía descubrir si los niños estaban } \\
\text { atentos. }\end{array}$ & $\begin{array}{l}\text { Ahora una ojeada hasta para observar al } \\
\text { que esta ocioso }\end{array}$ \\
\hline $\begin{array}{l}\text { Antiguamente la moral sólo estaba en } \\
\text { preceptos. }\end{array}$ & Yhoy se halla en la práctica \\
\hline $\begin{array}{l}\text { El desorden era siempre el resultado del } \\
\text { método vicioso de enseñanza. }\end{array}$ & $\begin{array}{l}\text { Ahora el orden más perfecto se inspira en } \\
\text { todos los movimientos. }\end{array}$ \\
\hline $\begin{array}{l}\text { Concluyo pues que un cuadro semejante no puede menos que arrebatar la atención } \\
\text { de los amantes de la juventud; pero si hay otro método que pueda mejorar el de } \\
\text { la enseñanza mutua, yo seré un panegirista, pues mi ambición se reduce a que se } \\
\text { mejore cada día la instrucción pública como que es la base de la felicidad de la } \\
\text { República. }\end{array}$ \\
\hline
\end{tabular}

En el método lancasteriano todo se hacia de forma gradual y sin sentir, comparado al sistema planetario.

En que cada cuerpo celeste atrae al de menos volumen, y lo mantiene en los límites fijos de su órbita. Todo se proporciona a las fuerzas respectivas. Un paso dado adelante la capacidad necesaria, al mismo tiempo que la armonía y el orden del conjunto amoldan el espíritu y la imaginación y dan desde temprano aquella exactitud de juicio que rechaza después, en todo orden de ideas, cuanto puede contribuir a la confusión y al desorden ${ }^{47}$.

\section{IMPULSO A LA ESCUELA LANCASTERIANA EN COLOMBIA}

Desde 1810 Bolívar estuvo enterado de la existencia del método lancasteriano a través de conversación personal que sostuvo con Lancaster en Londres el 26 o 27 de septiembre. "En un encuentro en la casa de Miranda... José Lancaster explicaba a los diplomáticos venezolanos (Bolívar, Andrés Bello y Luís López Méndez) la esencia de su sistema pedagógico"48.

Desde el congreso de Cúcuta se decretó el establecimiento de escuelas de primeras letras con el método lancasteriano. Las primeras escuelas con este método aparecen en 1821 en Bogotá y Mariquita; en 1822 en Cota. En 1823 lograron una mayor expansión sin llegar a sobrepasar en ningún año las que se establecían por el método antiguo.

47 Método de enseñanza mutua, El Conductor, n 2, p. 7.

* Salcedo Bastardo J. L., El primer deber: con el acervo documental de Bolivar sobre educación, Caracas, Ediciones de la Universidad Simón Bolivar, 1973, p. 143. 
Como se señaló, fray Sebastián Mora llegó para expandir el método en Colombia, y junto con Pedro Comettant -traído desde Francia por José Revenga, quien se encontraba en misión diplomática en éste país- desarrollaron un plan para la expansión de las escuelas en todo el territorio; mientras que el padre Mora se dedicaba a la apertura de escuelas y entrenamiento de maestros en el sur del país, especialménte Popayán y Ecuador, en las provincias de Loja y Cuenca, el señor Pedro Comettant lo hacia en las provincias del norté ${ }^{49}$. Así lo señala la Gaceta de Colombia en 1822:

Adquieren los conocimientos necesarios en este sistema muchos ciudadanos que hoy presiden las escuelas de Lancaster de las provincias de Tunja y Antioquia, y de algunas parroquias de las de Bogotá. Comettant habiendo sido destinado a establecer, y presidir la Escuela Normal de la ciudad de Caracas, ha partido a su destino por el Magdalena con el objeto de plantear escuelas en Cartagena y Maracaibo, para todo lo cual

- ha sido auxiliado suficientemente. El padre Mora ha sido nombrado preceptor de la Escuela Normal de Quito ${ }^{50}$ -

El fervor nacional por el método lancasteriano era total, hasta el punto de elaborar propuestas para suprimir escuelas existentes que funcionaban con el método antiguo y en su defecto establecerlas con el método lancasteriano. Así lo propone Estanislao Vergara el 5 de enero de 1822 en Bogotá, en donde solicitaba que se suprimiera una escuela antigua mal montada, a cargo de un maestro que no tenía conocimientos útiles para impartir a sus alumnos y que funcionaba en una pieza bastante grande que podría ser más útil a la lancasteriana, ya que

Más vale una escuela regular que muchas imperfectas y si no se perfecciona la enseñanza mutua, el gobierno pierde los gastos impedidos y ella se desacredita. Me parece de suma importancia que la escuela antigua se suprima, tanto más, cuando no es solo inútil sino perjudicial por el mal método de enseñar y por la nulidad del maestro ${ }^{51}$.

\footnotetext{
49 Bushnell, D., op. cit., p. 213.

51) Educación Pública, Gaceta de Colombia, Bogotá, 15 de septiembre de 1822, nº 48, p. 2.

5) AGN. Sección: República. Fondo: Ministerio de Instrucción pública, T. 107, folio 342v.
} 
La propuesta incluía además el traspaso del sueldo de este maestro por valor de trescientos pesos que se pagaban del tesoro público del ramo de temporalidades y se pasaran para pagar los gastos indispensables del nuevo establecimiento.

En mayo de 1824 el propio Lancaster se estableció en Caracas para fomentar su sistema de enseñanza mutua en dicha ciudad. Mantuvo correspondencia con Bolívar, que en ese momento se encontraba en el Perú y quien había decidido apoyarlo económicamente en su empresa educativa. El 16 de marzo de 1825, Bolívar le manifestó a Lancaster:

U. parece que ha de menester de protección para realizar sus designios benéficos, por tanto me adelanto a ofrecer a $U$. veinte mil duros, para que sean empleados a favor de la instrucción de los hijos de Caracas... serán entregados en Londres por los agentes del Perú, contra los cuales puede U. girar esta suma dentro de tres o cuatro meses... me será muy agradable adelantar a U. mayor suma de dinero con el mismo fin, siempre que $U$. juzgue útil el empleo de otra cantidad adicional... no tengo el menor inconveniente en promover la mejora de los establecimientos de la educación que U. dirige con su hermoso genio... Bolívar ${ }^{52}$.

El trabajo pedagógico de Lancaster en Caracas no tẹrminó bien, ni con Bolívar, ni con la municipalidad; la situación se agudizó cuando el Libertador solicitó en 1827 cuentas del dinero invertido por Lancaster cuando se le anunció que este viajaba a Estados Unidos ${ }^{53}$. Sin embargo, durante su estadía en Caracas, mantuvieron correspondencia con frecuencia lo que Lancaster le informaba a Bolívar sobre sus progresos y su trabajo pedagógico, bien fuera, él mismo como tutor o formando maestros.

El siete de enero de 1826 le informaba Lancaster a Bolívar: "tengo ocho muchachos nativos de Colombia, que viven en mi casa, que comen en mi mesa, y para quienes soy como un padre, pues la mayor parte de los que les dieron el ser fueron cobardemente asesinados por los españoles. Están estudiando para maestros de escuela..." ${ }^{54}$. En mayo del mismo año le confirmaba: "He

\footnotetext{
52 Al Señor Lancaster, Correo del Magdalena, Cartagena, 22 de septiembre de 1825, nº. 19, p. 3.

$\$ 3$ Salcedo Bastardo, J. L., op. cit., p. 433.

54 Ibid., p. 386.
} 
adoptado a unos doce jóvenes colombianos como si fueran mis propios hijos... en los días festivos van a su casa y su enseñanza religiosa queda únicamente al cuidado delos padres de familia y parientes. Yo no enseño doctrina: la sana moral y las lecturas útiles son mis únicas oraciones" ${ }^{\text {"5 }}$.

Mientras tanto en Bogotá se expresaba en los informes oficiales total optimismo con respecto al avance de la educación y la implementación del método lancasteriano. El secretario del interior, en 1826, consideraba que

ellas se han extendido a todas aquellas parroquias que poseen medios para sostener al maestro, y en la mayor parte de nuestras principales ciudades existen escuelas por el método lancasteriano...Gracias a la magnificencia del Libertador Presidente, en Caracas su patria debe estarse formando una escuela por el mismo Lancaster, que podría servir de modelo a las demás, si como esperamos, el director publica sus trabajos y sus nuevas observaciones ${ }^{56}$.

La vigencia del método lancasteriano se reconfirmó plenamente en el plan de estudios de 1826, en donde quedó estipulado en el artículo 12 que en todas las escuelas del país se observaría exclusivamente el método lancasteriano y para ello el gobierno se comprometía a enviar todos los materiales necesarios para su implementación, incluidos cartillas, pizarras, tablas, pitos, campanas y demás.

El periódico El Constitucional reportaba en julio de 1827 que en Colombia existían 52 escuelas por el método de enseñanza mutua y 434 del antiguo método, "que se ha mandado abolir progresivamente sustituyendo el primero conforme al reglamento orgánico de las escuelas el 3 de octubre último"57. Aun en este informe lo que se observa es que el método lancasteriano ni logró suplantar el antiguo, ni se estableció en todas las provincias de Colombia.

Aún así, el padre Mora y Pedro Comettant cumplieron su cometido de establecer el mayor número de escuelas en un periodo relativamente corto entre

55 Ibíd., pp. 400 - 401.

56. Bushnell, D., op. cit., p. 213.

57 Exposición que el secretario del interior hace al congreso, en El Constitucional, Bogotá, 19 de julio de $1827, \mathrm{n}^{\circ} .151, \mathrm{p} .1$. 
1820 y 1827 , como aparece en el cuadro ${ }^{1}$ el cual se elabora a partir de los reportes enviados al gobierno sobre establecimientos de escuelas, publicados en la Gaceta de Colombia.

Cuadro 1 Establecimiento de escuelas lancasterianas, $1821-1827^{58}$.

\begin{tabular}{|c|c|c|c|c|c|c|c|c|}
\hline Departamentos & Años & 1821 & 1822 & 1823 & 1824 & 1825 & 1826 & 1827 \\
\hline \multirow[t]{2}{*}{ Cundinamarca } & $\begin{array}{l}\text { Provincia de } \\
\text { Antioquia. }\end{array}$ & $\theta$ & & $\begin{array}{l}\text { Santafé de } \\
\text { Antioquia, } \\
\text { Medellín, } \\
\text { Rionegro } \\
\end{array}$ & & & & \\
\hline & $\begin{array}{l}\text { Provincia de } \\
\text { Bogotá }\end{array}$ & Bogotá & Cota, & \begin{tabular}{|l} 
Bogotá \\
(barrio la \\
Catedral, \\
Nieves, \\
San Barto- \\
lomé, San \\
Francisco), \\
Zipacón \\
Serrezuela, \\
Cáqueza, \\
Choachí, \\
Zipaquirá, \\
Ubaté, \\
Nemocón, \\
Cota, \\
Guaduas, \\
La Vega \\
\end{tabular} & & & & , \\
\hline & \begin{tabular}{|l|}
$\begin{array}{l}\text { Provincia de } \\
\text { Mariquita }\end{array}$ \\
\end{tabular} & Mariquita & & & & $\begin{array}{l}\text { Honda, } \\
\text { Ortega }\end{array}$ & & . \\
\hline & $\begin{array}{l}\text { Provincia de } \\
\text { Neiva }\end{array}$ & & & & $\begin{array}{l}\text { Neiva, } \\
\text { Villavieja } \\
\text { y Yaguara }\end{array}$ & & & \\
\hline \multirow[t]{3}{*}{ Cauca } & $\begin{array}{l}\text { Provincia de } \\
\text { Popayán }\end{array}$ & . & & Popayán & Cali, & & & $\begin{array}{l}\text { Popayán } \\
\text { ( } 3 \text { es- } \\
\text { cuelas) }\end{array}$ \\
\hline & $\begin{array}{l}\text { Provincia de } \\
\text { Chocó }\end{array}$ & & & & & & & \\
\hline & $\begin{array}{l}\text { Provincia de } \\
\text { Pasto }\end{array}$ & & & & & & & \\
\hline
\end{tabular}

58 Obra educativa de Santander. Bogotá: Fundación Francisco de Paula Santander, 1990. 


\begin{tabular}{|c|c|c|c|c|c|c|c|c|}
\hline Departamentos & Años & 1821 & 1822 & 1823 & 1824 & 1825 & 1826 & 1827 \\
\hline & $\begin{array}{l}\text { Provincia de } \\
\text { Buenaven- } \\
\text { tura }\end{array}$ & & & - & & & & \\
\hline $\begin{array}{c}\text { Boyacá. } \\
\therefore \\
\therefore \\
\therefore\end{array}$ & $\begin{array}{l}\text { Provincia de } \\
\text { Tunja } \\
\text { Pat } \\
.\end{array}$ & 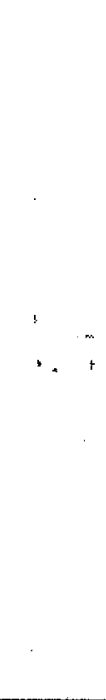 & $=$ & $\begin{array}{l}3.4 \\
\cdots \\
\cdots \\
\cdots\end{array}$ & $\begin{array}{l}\text { Tunja, } \\
\text { Villa de } \\
\text { Leiva, } \\
\text { Rami- } \\
\text { riquí, } \\
\text { Tibaná, } \\
\text { Gua- } \\
\text { chetá, } \\
\text { Lengua- } \\
\text { zaque, } \\
\text { Chiquin- } \\
\text { quirá, } \\
\text { Sativa } \\
\text { Norte, } \\
\text { Sativa } \\
\text { Sur, Soa- } \\
\text { tá, Santa } \\
\text { Rosa, } \\
\text { Cerinza, ' } \\
\text { Duitama }\end{array}$ & 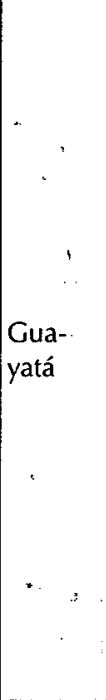 & Tenza & 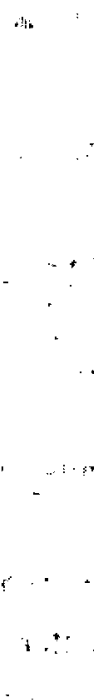 \\
\hline$. \quad+$ & $\begin{array}{l}\text { Provincia } \\
\text { del Socorro }\end{array}$ & & & Socorro & $\begin{array}{l}\text { Socorro, } \\
\text { Vélez }\end{array}$ & ' & & \\
\hline$\therefore$ & $\begin{array}{l}\text { Provincia de } \\
\text { Pamplona }\end{array}$ & a. & $\therefore$ & . & $\begin{array}{l}\text { Pamplo- } \\
\text { na }\end{array}$ & . & $\begin{array}{l}\text { Pam- } \\
\text { plona }\end{array}$ & \\
\hline : & $\begin{array}{l}\text { Provincia de } \\
\text { Casanare }\end{array}$ & , & &. & $\begin{array}{l}\text { Nunchía, } \\
\text { Bravo }\end{array}$ & $\because$ & $i$ & \\
\hline Istmo .... & $\begin{array}{l}\text { Provincia de } \\
\text { Panamá }\end{array}$ & & & & : & Panamá & & \\
\hline . & $\begin{array}{l}\text { Provincia de } \\
\text { Veraguas } \\
\end{array}$ & & & Veraguas & $\cdots$ & $\therefore$ & & \\
\hline Magdalena & $\begin{array}{l}\text { Provincia de } \\
\text { Cartagena }\end{array}$ & & & Cartagena & : & $\begin{array}{l}\text { Carta- } \\
\text { gena. }\end{array}$ & & \\
\hline . & $\begin{array}{l}\text { Provincia de } \\
\text { Santa Marta }\end{array}$ & & & - & Mompox & $v^{*}$ & ' & \\
\hline . & $\begin{array}{l}\text { Provincia de } \\
\text { Riohàcha }\end{array}$ & & & & $\therefore$ & & & \\
\hline
\end{tabular}

De acuerdo con las estadísticas del departamento del Cauca en 1827, se estaba muy distante de la generalización del método lancasteriano en Colombia, incluso la expedición de leyes que la aprobaban durante el periodo. En el cuadro 2 se observa el número de escuelas abiertás, el método y el número de niños y niñas en el departamento del Cauca específicamente. 
Cuadro 2 Escuelas de primeras letras, método y alumnos en el departamento del Cauca para el año de $1827^{59}$.

\begin{tabular}{|l|c|c|c|c|c|c|c|}
\hline \multirow{2}{*}{ Provincias } & \multicolumn{2}{|c|}{ Niños } & Niñas & \multicolumn{4}{c|}{ Alumnos } \\
\cline { 2 - 8 } & Lancasteriana & Antigua & Mixto & $\begin{array}{c}\text { En las } \\
\text { primeras }\end{array}$ & $\begin{array}{c}\text { En las } \\
\text { segundas }\end{array}$ & $\begin{array}{c}\text { En la } \\
\text { tercera } \\
\text { alumnos } \\
\text { de ambos } \\
\text { sexos }\end{array}$ \\
\hline Popayán & 3 & 31 & 1 & 234 & 1139 & 99 & 1472 \\
\hline Pasto & 0 & 15 & 0 & 0 & 476 & 0 & 476 \\
\hline B/ventura & 0 & 11 & 0 & 0 & 310 & 0 & 310 \\
\hline Total & 3 & 57 & 1 & 234 & 1925 & 99 & 2258 \\
\hline $\begin{array}{l}\text { Nota: no se incluyen en la anterior tabla las establecidas en la provincia del choco por ignorarse } \\
\text { cuántas son y, por consiguiente, el número de niños que hay en ellas. Todas las escuelas que constan } \\
\text { en estado, a excepción de muy pocas se han establecido en el gobierno de la republica y bajo el } \\
\text { régimen constitucional y conforme a la ley de la materia. }\end{array}$ \\
\hline
\end{tabular}

De 1827 a 1835 continuó el establecimiento de escuelas con el método lancasteriano en Riohacha, Panamá, Guayatá, Labranzagrande, Oiba, Bucaramanga, San José y Quibdo. Es importante resaltar en la escuela de Guayatá la participación de la junta curadora, del cura párroco, de los vecinos y de padres de familia, así lo registra la Gaceta de la Nueva Granada en 1833.

La junta curadora del distrito parroquial de Guayatá participa al gobierno haberse establecido allí una escuela de primeras letras, conforme al método de Bell y Lancaster. El establecimiento ocupa una sala espaciosa y decente, posee todas los útiles necesarios para que los alumnos puedan recibir las lecciones, según el indicado método, y el maestro goza de una dotación anual de $\$ 300$ que le ha sido asegurada por la generosidad de los vecinos de aquella parroquia, y de su venerable párroco doctor Pablo Calderón. Los objetos de tal establecimiento son constantemente sostenidos por el influjo de este párroco, por el celo de la junta curadora, por la cooperación del vecindario y por los esfuerzos reunidos de todos ${ }^{60}$.

59 El Conductor, Bogotá: del 19 de julio de 1827, n. 151, p. 1.

60 Establecimiento de una escuela de primeras letras en Guayatá, Gaceta de la Nueva Granada, $n^{\circ} .110$, 3 de noviembre de 1833, en Obra educativa de Santander. Bogotá: Biblioteca de la Presidencia de la República, 1990. T.2, p. 176. 
En la cita anterior se resalta el sostenimiento del maestro por los padres de familia y por el cura párroco.

\section{Funcionamiento de la escuela lancasteriana}

La escuela lancasteriana funcionaba con un reglamento específico ${ }^{61}$, el cual contemplaba los principios que se deberían observar: la asistencia diaria a la escuela en cada una de las clases, la que era tömada por'los monitores; el horario, que iba de 8:45 de la mañana hasta cuatro de la tarde, se solicitaba a los padres de familia el mayor cumplimiento para evitar el desorden; los niños que faltaban durante dos días consecutivos sin causa legítima eran despedidos de la escuela ${ }^{62}$.

Los monitores deberían registrar la asistencia al culto religioso cada domingo y en caso de que un niño no hubiẹse asistido a cumplir las prácticas de la doctrina religiosa, se citaba a los padres quienes debían explicar lo sucedido - so pena que el niño fuese retirado de la escuela, dado que para la escuela lancasteriana era de vital importancia el cumplimiento de esta regla.

Ningún niño podía ausentarse de la escuela, excepto en caso de enfermedad. Los niños que se ausentaban con permiso del maestro debían reponer el tiempo después de terminada la jornada escolar hasta completar el número de horas perdidas, acompañados por el monitor.

El método utilizaba premios y castigos: "Para algunos niños es un aliciente el placer de sobrepasar a sus compañeros y de obtener la aprobación de sus maestros; pero para promover una emuláción más general, se premia a todo niño que se distingue en saber su lección, o por su conducta ordenada en la escuela" ${ }^{63}$. Se entregaban cédulas de valor nominal a los alumnos que lo merecían. Estas cédulas se cambiaban por un valor en dinero o por otro tipo de estímulos de acuerdo con el nivel o situación que lo hubiera hecho ser acreedor del premio. Las recompensas que podían recibir eran "libros, gomas, camisas, medias, cortaplumas y artículos varios" ${ }^{\prime 2}$. Se destinaba un

\footnotetext{
61 Lancaster, J., op. cit., p. 85 - 105.

62 Enseñanza Mutua. Correo de Bogotá, 23 de mayo de 1822, nº. 147, p. 487.

63 Lancaster, J. op. cit., p. 94.

ot Ibid., pp. 96-97.
} 
día para la entrega de premios iniciando por los monitores. Una vez recibidos los premios, los niños eran llevados por sus monitores al salón de clase y allí se anunciaba en voz alta el concepto sobre el cual habían sido premiados, se les hacían dar varios vueltas al salón y luego se despachaban para sus casas.

Cada escuela debería tener una librería organizada por la comisión de la escuela a fin de controlar el tipo de libros que circularían en ella. Los préstamos de libros se utilizaban como un premio, sobre todo a los monitores, quienes podían llevarlos prestados a la casa ${ }^{65}$.

Los principales castigos utilizados era la pérdida de las cédulas y la confinación (arresto) después de las horas de clase. La última parte de la jornada escolar se dedicaba a premiar y castigar a los niños:

los buenos reciben un parco de premio y vuelven a los asientos, los malos se clasifican en divisiones correspondientes con el numero de sus ofensas y se les requiere a que paguen un parco por cada ofensa; los que así son separados y los que no tienen parco ...se les confina un cuarto de hora por cada ofensa que digan han cometido, los parladores juguetones y ociosos son sentenciados a un cuarto de hora de confinación por cada una de las ofensas arriba mencionadas. Los niños desposeídos son sentenciados a lavarse las manos y la cara y a la confinación de media hora, los holgazanes son reprobados o reprendidos por el maestro, según el caso lo requiera; son confinados a razón de tres horas, por cada falta a la escuela. En todo caso pueden libertarse de la confinación, si poseen billetes de premio, dándoles a razón de un parco por cada detención de un cuarto de hora... la desobediencia de los monitores y subalternos a los monitores generales cuesta seis parcos, la parcialidad de los monitores o los falsos informes, ocho parcos ${ }^{66}$.

Todo niño tenía derecho a apelar en caso que sintiera que el informe del monitor no se ajustaba a la verdad; para ello debía buscar testigos en su defensa $y$, de acuerdo con ello, el maestro presentaba su respuesta. Si el niño tenia la razón so se le aplicaba el castigo; de lo contrario, el niño debía quedarse en la escuela después de la jornada el doble de tiempo. El horario de actividades estaba organizado de la siguiente manera:

\footnotetext{
65 Ibid., pp. 97-98.

66 Ibíd., pp. 98-99.
} 
Cuadro 3 Orgánizáción de actividades en la: Escuela Lancasteriana ${ }^{67}:$ :

\begin{tabular}{|c|c|c|c|c|c|c|}
\hline Horas & unes & Martes & Miércoles & Jueves & Viernes & Sábado \\
\hline 9 a.m. & \multirow{2}{*}{\multicolumn{5}{|c|}{$\begin{array}{l}\text { Escritura } \\
\text { Se cierra puerta de la escuela, el maestro lee en voz alta un capítulo de } \\
\text { la éscritura, déspués de lo cual toda lá escuela"comienza a escribir las } \\
\text { tablas aritméticas y al mismo tiempo se pasa lista a los niños de la clase. }\end{array}$}} & 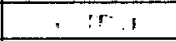 \\
\hline $\begin{array}{l}91 / 4 \text { à } \\
91 / 2\end{array}$ & & & & & & 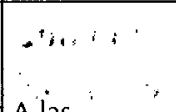 \\
\hline $\begin{array}{l}91 / 2 \mathrm{a} \\
10^{1 / 2} \\
\end{array}$ & \multicolumn{5}{|c|}{ Los niños se dividen en semicírcúlos para la lecturà. - . . . . } & $\begin{array}{l}\text { nueve de } \\
\text { la mañana, }\end{array}$ \\
\hline $\begin{array}{l}10 \frac{1 / 2}{a} \\
103 / 4\end{array}$ & \multicolumn{5}{|c|}{$\begin{array}{l}\text { Vuelvén' a sus asientos, 'y las primeras cuatro clases se emplean en } \\
\text { escribir dictando mientras que la } 5, ; 6^{a}, 7^{\mathrm{a}} \text { y } 8^{\mathrm{a}} \text { formadas en escribir } \\
\text { ejemplos dictados. }\end{array}$} & $\begin{array}{l}\text { el maestro } \\
\text { recibía las } \\
\text { solicitudes }\end{array}$ \\
\hline $\begin{array}{l}10.3 / 4 \text { a } \\
11 \frac{1}{1 / 2}\end{array}$ & \multicolumn{4}{|c|}{$\begin{array}{l}\text { Las diez clases de numerar se dividen entonces en } \\
\text { semicírculos y trabajan sus sumas extemporáneamente. }\end{array}$} & \begin{tabular}{|l|} 
Se repiten \\
las tabla \\
aritméticas
\end{tabular} & $\begin{array}{l}\text { de admisión } \\
\text { dè lośn niños } \\
\text { que desea- }\end{array}$ \\
\hline $\begin{array}{l}11 \frac{1}{1 / 2} \text { a } \\
11^{3 / 4}\end{array}$ & \multicolumn{5}{|c|}{$\begin{array}{l}\text { Las clases vuelven a sus asientos y los monitores de la lectura de la } 7^{\mathrm{a}} \text { y. } \\
8^{\mathrm{a}} \text { clase se colocan en frente de lá mesa y leen en vón alta un pedazo de } \\
\text { la sagrada escritura después de ló cual el maestro lés cuestiona. }\end{array}$} & $\begin{array}{l}\text { resar } \\
\text { uela, } \\
\text { do. }\end{array}$ \\
\hline $\begin{array}{l}113 / 4 \mathrm{a} \\
12 \mathrm{a} . \mathrm{m} . \\
\end{array}$ & \multicolumn{5}{|c|}{$\begin{array}{l}\text { Los niños buenos y malos son llamados de sus asientos y premiados o } \\
\text { castigados correspondientemente. En el tiempo mismo toda la escuela } \\
\text { principia a éscribir las tablás aritméticás, \&c: dictadas y a las } 12 \text { la } \\
\text { escuela se levanta. }\end{array}$} & 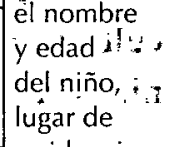 \\
\hline 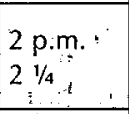 & \multicolumn{5}{|c|}{$\begin{array}{l}\text { Se reúnen los niños toman sus asientos en sus respectivas clases de } \\
\text { escritura y cómienzan a escribir dictado al mismo tiempo que los } \\
\text { monitores de la lecturá se ejercitan en sus puestos. }\end{array}$} & $\begin{array}{l}\text { icia, } \\
\text { ede } \\
\text { Ires } y_{i}\end{array}$ \\
\hline & \multicolumn{5}{|c|}{$\begin{array}{l}\text { Se cierra la puerta de la escuela, después de lo cual todos los niños } \\
\text { principian a escribir làs tablas aritméticas. }\end{array}$} & que, \\
\hline $\begin{array}{lll}2 & 1 / 2 \\
3 & 1 / 2 \\
-1 / 2\end{array}$ & & & $\begin{array}{l}\text { Los niños se } \\
\text { dividen en } \\
\text { semicírcu- } \\
\text { los para la } \\
\text { lectura. }\end{array}$ & $\begin{array}{l}\text { Los niños } \\
\text { se dividen } \\
\text { en semicír- } \\
\text { culos para } \\
\text { deletrear }\end{array}$ & $\begin{array}{l}\text { Los niños se } \\
\text { dividen en se- } \\
\text { micírculos para } \\
\text { la lectura } \\
\end{array}$ & $\begin{array}{l}\text { Con tales } \\
\text { datos se } \\
\text { formaba una } \\
\text { lista de so- } \\
\text { licitudes, se }\end{array}$ \\
\hline $\begin{array}{ll}31 / 2 a \\
4 & 1 / 2 \\
\end{array}$ & \multicolumn{5}{|c|}{$\begin{array}{l}\text { Los niños vuelven a su clase de escritura y los mejores monitores de la } \\
7^{\mathbf{a}} \text { y } 8^{\mathrm{a}} \text { clases escriben entonces sobre el papel. }\end{array}$} & \multirow{3}{*}{$\begin{array}{l}\text { licitudes, se } \\
\text { examinaba } \\
\text { a los niños } \\
\text { en su nivel } \\
\text { de conoci- } \\
\text { miento para } \\
\text { ubicarlos } \\
\text { en la clase } \\
\text { correspon- } \\
\text { diente y se } \\
\text { informaba } \\
\text { a los padres } \\
\text { sobre la } \\
\text { respuesta a } \\
\text { la solicitud, } \\
\text { si el niño era } \\
\text { admitido. } \\
\text {.... }\end{array}$} \\
\hline 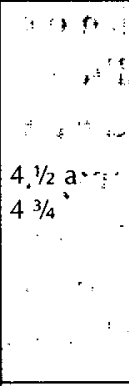 & $\begin{array}{l}\text { Los mo-: } \\
\text { nitores se } \\
\text { colocan al } \\
\text { frente de la } \\
\text { mesa para } \\
\text { leerle al } \\
\text { maestro de } \\
\text { la misma } \\
\text { forma } \\
\text { que en la. } \\
\text { mañana. } \\
\end{array}$ & $\begin{array}{l}\text { Los mo- } \\
\text { nitores se } \\
\text { coloćan al } \\
\text { frente de la } \\
\text { mesa para } \\
\text { leerle al } \\
\text { maestro los } \\
\text { diez man- }\end{array}$ & $\begin{array}{l}\text { Los monito- } \\
\text { res se colo- } \\
\text { can al frente } \\
\text { dé lá miesa } \\
\text { para leerle. } \\
\text { al maestro } \\
\text { de la misma } \\
\text { forma que = } \\
\text { en la maña- } \\
\text { na. }\end{array}$ & $\begin{array}{l}\text { Los mo- : } \\
\text { nitores se } \\
\text { colocan al } \\
\text { frente de la" } \\
\text { mesa para } \\
\text { leerle al } \\
\text { maestro los } \\
\text { diez man- } \\
\text { damientos y } \\
\text { las reglas de } \\
\text { al escuela. }\end{array}$ & $\begin{array}{l}\text { Los monitores } \\
\text { se colocan al } \\
\text { frente de' la } \\
\text { mesa para leer- } \\
\text { le al maestro, } \\
\text { de la misma } \\
\text { forma que en } \\
\text { la mañana. }\end{array}$ & \\
\hline 4 & \multicolumn{5}{|c|}{$\begin{array}{l}\text { Los niños bienos y malos son llamados de sus ásientos, y premiados o } \\
\text { castigados correspondientemente. En el tiempo mismo toda la escuela } \\
\text { principia a escribir las tablas aritméticas, \&c. después de lo cual el } \\
\text { maestro lee un capítulo de las sagradas escrituras y a las } 5 \text { la escuela se } \\
\text { levanta. }\end{array}$} & \\
\hline
\end{tabular}

67 Ibíd., pp. 100-105. 
Todos los sábados a las nueve de la mañana, el maestro recibía las solicitudes de admisión de los niños que deseaban ingresar a la escuela, registrando el nombre y edad del niño, lugar de residencia, nombre de los padres y religión que profesaban. Con tales datos se formaba una lista de solicitudes, se examinaba los niños en su nivel de conocimiento para ubicarlos en la clase correspondiente y se informaba a los padres sobre la respuesta a la solicitud; si el niño era admitido se entregaba a los padres una copia de las reglas que estos deberían cumplir: "enviar regularmente a sus hijos a las 9 de la mañana y a las dos de la tarde, excepto los sábados y atender a que tengan limpias las manos y la cara, peinados y pelones. Ningún niño puede ser admitido después de las $91 / 4$ y de las $2 \frac{114}{4}$ y los que son regulares en su concurrencia serán premiados" ${ }^{\prime 6}$.Ningún niño podía retirarse de la escuela sin permiso del maestro, a no ser por enfermedad. Los padres debían llevar los niños regularmente al culto público e instruirlos en los rudimentos de la religión y fomentar en los niños la obediencia a las reglas y órdenes de las escuelas ${ }^{69}$.

La instrucción religiosa y moral de los niños ocupaba un lugar privilegiado para los que asistían a la escuela lancasteriana; las lecciones se limitaban a la lectura y memorización de pasajes de las sagradas escrituras. El procedimiento que se utilizaba era a través de los interrogatorios sobre las lecciones que se estuvieran enseñando: "a una señal del monitor general de lectura, los monitores de sección toman en sus manos las tablas y proceden a preguntar a los niños sobre el objeto de la lección"70.

El principio de la escuela lancasteriana se basaba en el mantenimiento del orden y de la disciplina, a través del cual los estudiantes, bajo la dirección de un maestro, seguían un curso de instrucción mutua, ello significaba que la enseñanza se daba de manera compartida. Los estudiantes que mayores progresos tuvieran en la lectura, escritura, aritmética, compartían sus conocimientos con los menos aprovechados y colaboraban con el maestro en la administración de toda la escuela. De esta manera el maestro tenía la capacidad de atender entre 500 y 1000 niños en una sola escuela ${ }^{71}$.

68 Ibíd., pp. 86.

69 Ibid., pp. 86-87.

70 Ibíd., pp. 48-49.

$\because$ lbid., p. 33. 
Diariamente los monitores eran reunidos por su maestro para organizar el trabajo escolar. Los monitores de lectura de las clases más altas debían ser entrenados con mayor esmero en el método de interrogatorio bíblico.

Los monitores se dividían en generales o subalternos; los generales de la escuela y los subalternos tenían a su cargo la instrucción de algunos niños. Los monitores generales se subdividían en monitores generales de orden, que eran los delegados del maestro y responsables del orden de la escuela; el monitor general de lectura a cargo de esta sección; y el monitor general de aritmética, responsables del buen orden de los niños mientras están ocupados en ella. Entre de los monitores subalternos se encontraban los de escritura, aritmética, lectura y los inspectores que auxiliaban a los monitores de las clases en el examen de la escritura ${ }^{72}$. Para todos los monitores, el reglamento establecía los deberes que deberían cumplir en cada momento del día.

Los monitores se dirigían a los alumnos a través de lo que se llamaba las voces de mando, "las cuales eran particularmente inevitables, en las grandes escuelas, para dirigir los movimientos de los discípulos; estaban calculadas para conservar la atención de los alumno's"73. Existían voces de mando para pedir la lista de los niños buenos y malos. A cada orden del monitor, los alumnos debían ejecutar una acción. No existía posibilidad de diálogo, de raciocinio, ni de interpelación, lo único que se esperaba era el estricto cumplimiento de las órdenes al estilo militar. Si los niños se equivocaban, con la palabra vuélvanse, les hacían repetir la acción.

Textualmente, la voz de mando para pedir la lista de los niños buenos y malos, se expresaba así:

Niños citados - colgaderos - atención - marchen - frente como al principio [los niños llevan entonces sus manos a los cordoncitos que aseguran sus sombreros de sus espaldas. Sombreros: unen los cordoncitos y colocan sus sombreros sobre el atril a su frente].

\footnotetext{
72 Ibid., p. 62.

73 Ibíd., p. 79.
} 
Pónganse: llevan los sombreros sobre sus cabezas con ambas manos. Sombreros y fijenlos.

Manos abajo - atención - marchen - como antes ${ }^{74}$.

Existían voces de mando para comenzar el trabajo de la escuela: "tomen pizarras... dejen pizarras... manos abajo"; para hacer los exámenes de escritura, para salir a leer, para volver de la lectura, para ir a los semicírculos de aritmética, para volver de los semicírculos.

Las voces de mando al volver de la lectura eran:

Marchen: ellos se comparten en semicírculos.

Marchen: siguen en la dirección de sus asientos y se sitúan en los pasos detrás de las mesas, enfrente de los clavos de que cuelgan sus pizarras.

Frente: se vuelven hacia el monitor general.

Atención: como antes (el monitor hace una señal, para volver algunos niños a la derecha o izquierda según la ubicación de sus puestos)

Siéntense: se sientan.

Manos abajo: tomen pizarras, dejen pizarras, limpien pizarras \&c como al principio ${ }^{75}$.

Las palabras que se oían en el salón de clase durante el día escolar eran "atención, marchen, frente, como antes, dejen pizarras, limpien, tomen, levántense..."A través de este mecanismo se mantenía la escuela en total orden y obediencia, y sólo así se explica el principio en que se basaba, cuando se expresaba que los niños no tenían que pensar, pues el método era totalmente maquinal e insensible.

Los maestros y maestras de la escuela lancasteriana se escogían entre de las personas de mayor conducta moral y religiosidad. Debían ser sumisos, amantes de la verdad, la sinceridad y la honradez, capaces de ganar el amor de los niños para poderlos gobernarlos. En lo concerniente al nivel de instrucción, al maestro de las escuelas elementales sólo se exigía que supiera "lectura, aritmética y labor, no otra cosa se requería absolutamente de un

\footnotetext{
74 Ibíd., pp. 82-83.

75 Ibíd., p. 81.
} 
maestro o maestra de tales escuelas, que un perfecto conocimiento de aquellos ramos de instrucción; y tál' es la excelencia del sistema británico, que si la organización de la escuela se mantiene exactamente, bastaría aún un grado moderado de saber" "76.

Se esperaba de los maestros una actitud franca y bondadosa hacia' los padres de familia, a los cuales debería hacerles visitas amistosas, cooperando con ellos e induciendo los niños a los hábitos de aseo, diligencia y virtud: "Tal conducta debe así mismo producir una impresión favorable en los que asistan a la escuela y disponerlos a venir en su ayuda"77

Aunque el equipamiento de la escuela lancasteriana era totalmente descrito en la primera parte del Manual del sistema de enseñanza mutua, el periódico el Eco de Antioquia lo describe en una publicación de enero de $1823^{\star}{ }^{\star} \cdots$

La sala de la escuela está situada en lo bajo e interior, del colegio: tiene veinte y cinco varas de longitud, y nueve de latitud; hay en ella diez y ocho mesas en que escriben los niños, y otros tantos bancos en que se sientan: diez y ocho semicírculos en que se forman a leer; sesenta y cinco pizarras, sesenta y ocho lapiceros e igual número de lápices con que la generosidad del señor intendente del departamento ha dotado esta escuela, hay también cincuenta y ocho silabarios, y cartillas elementales de leer, escribir y contar, y treinta escudòs de distinción para los monitores, y niños primeros de cada clase ${ }^{78}$.

Figura1 Plano de la sala de clase de la escuela Lancasteriana.

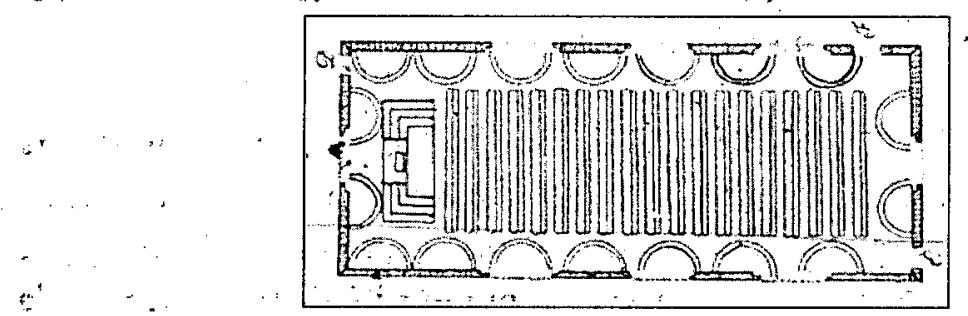

Fuente: Lancaster, J., Manual del Sistema de Enseñanza mutua aplicado a las escuelas primarias. Bogotá, S.S. Fox, 1826, p. 121.

\footnotetext{
76 Ibíd., pp. 83-84.

"7 Ibíd., pp. 84.

78 Escuelas, en El Eco de Antioquia. 26 de enero de 1823, nº.36, p. 148.
} 
El salón de la escuela debería ser cuadrilongo como aparece en la figura 1, de manera que facilitara la organización del mobiliario. Se sugería la adecuación de un patio donde los niños pudieran recrearse, el cual debería estar protegido por un muro alto, tener disponibilidad de agua para facilitar el lavado de caras y manos de los niños y tener protección del sol y la lluvia mientras jugaban ${ }^{79}$.

Los semicírculos debían contener entre diez y doce niños, podían hacerse "de madera o de hierro, embutido en el suelo a nivel del pavimento o señalando con una raya profunda, lo que será mejor. Los niños se colocan para leer sobre estos semicírculos, el radio de cada semicírculo debe ser de cuatro pies debiendo quedar un espacio de dos y medio pies entre cada uno de ellos"80.

\section{Obstáculos para el establecimiento de escuelas lancasterianas}

El equipamiento de la escuela requería mucho más de lo expresado en el Eco de Antioquia, pero aun así la nueva República no disponía de fondos para adquirir estos implementos y para adecuar la escuela. En muchos lugares ni siquiera se contaba con pizarras porque en el país no las había. La mayoría de materiales eran traídos desde Nueva York. Uno de estos pedidos fue publicado en la Gaceta de la Nueva Granada en 1834: "De la primera remesa de pizarras y lápices para las escuelas primarias del Estado recibida de Nueva York en Santa Marta y que se anunció en la gaceta última, se ha mandado hacer la siguiente distribución entre las provincias litorales o más próximas a la costa"11 y se enumeran las provincias con el número de pizarras y lápices que recibían anunciando que mas adelante se le enviarán cuadros de lectura y manuales para su organización.

El periódico El Fósforo de Popayán criticaba en 1823 que tuvieran que traerse las pizarras del extranjero, contando en Colombia con las materias primas necesarias para su fabricación, "las riberas del Dagua es uno de los lugares en donde se ven en más abundancia; hay puntos donde se encuentran las

\footnotetext{
79 Lancaster, J., op. cit., p. 13.

${ }^{80}$ Ibíd., pp. 20-21.

81 Gaceta de la Nueva Granada, n 135, 27 de abril de 1834. Obra educativa de Santander. Bogotá, T.2, Fundación Francisco de Paula Santander, 1990.
} 
capas de estas piedras desprendidas naturalmente de los cerros y en estado que con poquísima preparación podrían formarse una cantidad de láminas suficiente para proveer todas las escuelas que puedan establecerse en el Valle del Cauca"82.

El país no tenía recursos: "La escasez y atraso de los fondos de propios es el obstáculo más poderoso que encuentra la municipalidad para establecer en esta capital la escuela de primeras letras conforme a la ley del soberano congreso, como también para proveer otras obras que concibe de la mayor importancia y utilidad pública"\$3.. La esperanźa de montar escuelas quedaba puesta en el vecindario, pero éste a su vez se encontraba pobre y aniquilado. Se esperaba que la municipalidad hiciera gestiones para entregar alguna casa de las secuestradas para que allí se estableciera la escuela de primeras letras en 1821.

Los reportes del estado de la escuela de.Maracaibo, en 1824, manifestaban que existía una escuela lancasteriana sostenida a'costas de miserias y privaciones "por algunas mezquinas dádivas con que le contribuyen los padres de los niños" 84 y que aunque los maestros se hábían formado en el método lancasteriano, fúnciona una con el antiguo pör no poder disponer de otros recursos.

En Caracas, el mismo José Lancaster encontró dificultadés para implementar su sistema por incomprensión del método y porque "la municipalidad no cumplió con los términos del contrato, en cuya exigencia el Libertador salvó la situación, mandando indemnizar al sabio inglés con dinero de sus personales haberes" ${ }^{\prime 3}$.

Documentos que expresan los inconvenientes para el establecimiento del método lancasteriano en la escuela de Mérida manifiestan que desde 1822 se

\$2 Educación Literaria, en El Fósforo de Popayán, Popayán, 13 de febrero de 1823, n. 3, pp. 17-18.

83 AGN. Sección: República. Fondo: Ministerio de Instrucción pública, T. 106, folio 201 r.

84 AGN. Sección: Répública. Fondo: Ministerio de Instrucción pública, T. 106. folio 201r.

*5 GrisanTl, A., Resumen histórico de la instrucción pública en Venezuela, Bogotá, Editorial Iquema, 2a ed., 1950., p 111. 
había venido solicitando al reverendo obispo, por intermedio de la municipalidad, para que estableciera la escuela, pero ello fue imposible porque, por una parte, no se contaba con fondos suficientes y, por la de otra, el obispo consideraba inútil e ineficiente el método de enseñanza mutua ${ }^{86}$. La fecha de este reporte corresponde a 1827.

El otro inconveniente para la apertura de escuelas lancasterianas fue la ausencia de maestros formados en el método, combinado con el hecho de que los que se formaban podrían esperar años hasta que se destinaban fondos para la apertura de la escuela ${ }^{87}$, como el caso del joven maestro que viajo de Medellín a Bogotá para aprender el método y tuvo que esperar meses mientras se recolectaba el dinero entre los vecinos para adecuar la pieza destinada a la escuela.

Los maestros formados en el método lancasteriano, y que abrían la escuela para su funcionamiento, no veían con buenos ojos el que a los tres meses ya se les estuviera examinando pues igual manifestaban no contar con los haberes necesarios para impartir la instrucción:

Ojalá que los auxilios que se me debían haber suministrado hubieran correspondido a las benéficas disposiciones del gobierno ¡ojala que la aplicación, constancia y permanencia de los jóvenes de esta escuela correspondiesen a los esfuerzos y sanas intenciones de las cuales me vi adornado desde el momento en que me encargue de esta escuela de primeras letras ${ }^{88}$.

Hacia 1826 Riohacha no contaba con escuelas lancasterianas por no disponer de maestros formados en el método lancasteriano, situación que obligó al intendente a publicar aviso en la Gaceta de Cartagena, para que quien estuviera interesado en obtener el cargo se presentara a solicitarlo ${ }^{89}$.

En carta a José Manuel Restrepo, proveniente de Cumaná (Venezuela), se expresaban los inconvenientes por los cuales hacia 1828 no se habían

\footnotetext{
86 AGN. Sección: República. Fondo: Ministerio de Instrucción pública, T. 106, folio 86r.

87 Aviso Oficial, en El Eco de Antioquia, 15 de diciembre de 1822, nº. 30, p. 124.

88 Escuela Normal, Gaceta de Cartagena, Cartagena, 25 de septiembre de 1824, n. 163, p. 1 .

Áviso, Gaceta de Cartagena, Cartagena, 7 de enero de 1826, nº. 229, p. 4.
} 
establecido escuelas en ningún cantón del departamento por el método de Bell y Lancaster:

- $1^{\circ}$ porque la alteración del orden político en los dos últimos años no lo ha permitido, $2^{\circ}$ por no haberse recibido en esta intendencia los modelos a ejemplares de dicho método que debió remitir el gobierno . conforme al artículo 12 del decreto orgánico o reglamento del plan de estudios y $3^{\circ}$ por que sin los modelos a que se refiere el motivo anterior no han podido formarse maestros para la instalación de una sola escuela ${ }^{90}$.

Los mayores obstáculos para la implementación al sistema lancasteriano pueden resumirse en la faltà de fondos para adecuar escuelas con todos los requerimientos exigidos tanto de adecuación del espacio como de materiales didácticos y la carencia de maestros formados en el método, que aunque existían algunas escuelas normales, no se contaba con los fondos necesarios para trasladarlos a los lugares donde recibirían el curso, o cuando podían tomarlo la escuela no estaba adecuada. Esta situación contribuyó a que se continuara con el uso del método antiguo, el cual no requería ninguna adecuación de espacio, ni de materiales especiales, ni formación del maestro y además le quedaba más fácil a los padres de familia contribuir con el pago de este maestro que por sus características ganaba menos que otro formado en el nuevo sistema.

\section{CRÍTICAS AL SISTEMA LANCASTERIANO}

El Manual del sistema de Enseñanza Mutua contemplaba que como que su escuela se proponía enseñar a leer, escribir y contar, los maestros solo debían manejar este tipo de conocimiento. Este elemento hizo que se empobreciera la formación de los maestros y se requiriera la mínima instrucción para ejercer su profesión. Aunque la escuela lancasteriana no enseñaba la doctrina cristiana, sino que se dejaba esta formación a cargo de los padres, se requería al maestro que tuviera todas las condiciones de la moral civil y religiosa, que demostrara ser de buenas costumbres y, ante todo, piadoso.

\footnotetext{
90 AGN. Sección: República. Fondo: Ministerio de Instrucción pública, T. 106, folio $216 \mathrm{r}$ y v.
} 
El surgimiento de las escuelas normales lancasterianas de este periodo no significaron un elemento importante, ni avanzaron la formación pedagógica de los maestros dado que el tiempo de preparación era muy corto y se debía dedicar básicamente a que los maestros mismos aprendieran a leer y escribir simultáneamente con los estudiantes que se desempeñarían como monitores. El grueso de la formación se dedicaba a recibir las instrucciones de la manera en que tendrían que poner a funcionar la escuela, el trabajo de los monitores, la organización de las clases, la organización de la biblioteca, la admisión de los niños, la entrega de premios y castigos, y la presentación de certámenes, entre otros aspectos.

Las instrucciones que recibían los maestros los entrenaban más para desempeñarse como capataz de una fábrica que para dirigir la formación de los niños y los jóvenes. Por tanto, no puede decirse que en los inicios de la República se tuviera un maestro distinto, formado, instruido y ante todo diferente del maestro colonial.

Con respecto a la función de los monitores, José María Triana exponía en 1824 que era

del todo imposible que un solo hombre pueda regir e instruir a un gran número de niños como el que está a su cargo: que los monitores que se han puesto para que le auxilien como son niños del mismo carácter de aquellos a quienes van a gobernar; no sirven de otra cosa que para divertirse unos con otros impunemente, protegiendo su ociosidad o encubriendo los defectos de los demás niños que les están recomendados; y que por estos conocimientos no encuentra otro arbitrio para facilitar la pronta educación de la juventud, sino es el de que se pongan unos jóvenes de fuera de la escuela instruidos que sirvan de monitores con el sueldo moderado de ocho pesos ${ }^{91}$.

Ante esta solicitud, José Manuel Restrepo respondió que no se contaban con fondos nacionales para hacer más aportes a la escuela y que cualquier solicitud que se hiciera al respecto debía cursarse ante el cabildo de la ciudad, que también debía aportar a la educación.

91 AGN. Sección: República. Fondo: Ministerio de Instrucción pública, T. 108, folio 282r. 
En Chile también se hicieron críticas al sistema lancasteriano en este mismo sentido, pues consideraban que al dejar la educación en manos de los monitores se le restaba calidad, quedaba incompleta y se malformaban los alumnos; consideraron insuficientes las pocas horas de instrucción que recibían los maestros y los monitores; inadecuado el hecho de que los monitores tuvieran que aprender y enseñar el mismo día, sobre todo manejando un número tan elevado de estudiantes, lo que los convertía en malos maestros y déspotas administradores; el tiempo dedicado a la enseñanza y los temas que se desarrollaban eran reducidos; censuraron las prácticas de premiar y castigar a los alumnos por los fracasos y adelantos que tuvieran ${ }^{92}$, mucho más si se manejaba el concepto de premiar con dinero a los que sobresalían y castigar con arresto a los que cometían las faltas y exponiendo a toda la escuela el motivo por el cual era castigados, ya que se les hacían colocar letreros a los niños con el nombre de la falta cometida y con dicho letrero debían pasearse por el salón para que los otros niños observaran, exponiéndolos al escarnio público.

El sistema lancasteriano no ofreció un desarrollo pedagógico en el sentido de la formación del hombre, del nuevo ciudadano que requería la República o el sujeto moderno de una nación libre e independiente. Sólo sirvió como una forma de administrar masivamente la enseñanza de la lectura, la escritura y las matemáticas a la población infantil de las clases pobres desde los inicios de la República y hasta mediados del siglo xix. El método fue maquinal, insensible, fabril, en el que solo se pronunciaban órdenes que los niños y niñas debían obedecer, situación que no era difícil de aprender pues a ello se estaba acostumbrado desde la época colonial; no, había nada que pensar, nada que preguntar, nada que analizar, pues el sistema estaba diseñado sólo para obedecer ¿Por qué se consideró que este sistema educativo formaría al nuevo ciudadano? El proyecto de nación no tenía nada que ver con el proyecto pedagógico que adoptó la República; habrían aportado más a la construcción del nuevo sujeto los postulados de educación social de Simón Rodríguez, que esta propuesta lancasteriana.

92 Amunategui Solor, D., op. cit., p. 23. 
Los padres y madres de familia y personas de la comunidad observaban que el método no enseñaba a leer y escribir, pero ellos consideraban que era por la falta de recursos, como lo relata $\mathrm{El}$ Conductor en 1827 :

Confesemos que el mal viene de la escasez de recursos. Escuelas sin útiles, sin disciplina y sin un competente número de silabarios jamás producirán útiles resultados; de aquí nacen los atrasos en la lectura, de que tanto se lamentan algunos, pues hallándose la escuela sin disciplina, los niños permanecen tan disipados como en el antiguo método, no habiendo recompensas que los estimulen y satisfagan su trabajo a los monitores, unos y otros descuidan de sus deberes, y finalmente no siendo abundante el número de silabarios, no tienen donde ejercitarse para aprender con perfección la lectura ${ }^{93}$.

En Chile, los padres de familia también mostraron su preocupación por la deficiente instrucción que recibían sus hijos en la escuela lancasteriana. Esto hizo que el gobierno pusiera en consideración estas quejas, lo que ocasionó que se tomara la decisión de dividir en dos secciones el Instituto Nacional en 1832: "una bajo el sistema antiguo, en la cual no debían admitirse sino 30 alumnos con una pensión mensual de dos pesos y otra gratuita, bajo el sistema lancasteriano, sin limitaciones del número de alumnos"94.

Teniendo en cuenta la decisión tomada, la junta directora de estudios presentaba al público los siguientes argumentos, cuestionando el sistema lancasteriano:

Por la mala organización y escasez de progresos que se observan en la escuela gratuita a causa del método de la enseñanza mutua adoptado en ella, la junta ha visto el resultado práctico de este sistema de enseñanza, que lejos de corresponder a las esperanzas, no solo ha retardado el aprendizaje de los alumnos, sino que éste, al fin, ha sido defectuoso: consecuencia natural de un método en que, abandonada la enseñanza de un niño al escaso saber de otro mayor, contrae vicios que no se le corrigen y en la lectura especialmente, sus progresos están restringidos

93 Enseñanza mutua, El Conductor, Bogotá, 27 de marzo de 1827, n. 16, p. 64 .

94 Amunategui Solor, D., op. cit., p. 197. 
por la corta capacidad de un monitor. Así, es que en el día se ven con dolor que apenas hay uno o dos en cada clase que sepa leer correctamente. En atención a esto, la dirección de estudios, ha tenido a bien, abolir en dicha escuela el método de la enseñanza mutua, limitando a setenta el número de sus alumnos, que es el máximo a que pueden extenderse la inmediata atención del maestro ${ }^{95}$.

Andrés Bello, Domingo Faustino Sarmiento y Simón Rodríguez fueron opositores al método lancasteriano. Simón Rodríguez pensaba que la enseñanza mutua era un disparate, ya que el interés de Lancaster estaba en hacer aprender la Biblia de memoria. Veía inadmisible el hecho de que los estudiantes fueran a la escuela a enseñar o a ayudar a enseñar en lugar de aprender. "Dar gritos y hacer ringorrangos", decía, no era aprender a leer ni a escribir. Criticaba el método memorístico, los ejercicios que hacían en la arena para entrenar la escritura y el uso que le daban a la pizarra ${ }^{96}$, pues todas estas técnicas no permitían el aprendizaje de los niños.

Consideraba que la deficiente formäción que recibía un maestro en el método lancasteriano lo hacia abandonar la profesión y volver "al oficio que tenían, alarmados de las preguntas que les acarreaba su nuevo ejercicio" 97 . Llamaba a estas escuelas, "las escuelas de vapor", a las que ubicaba en la categoría de escuelas "para la morralla-almacenes de muchachos, enseñándose unos a otros a gritar y los maestros... (digo mal) los preceptores, mandando (a uso de los pilotos) la maniobra: son escuelas de vapor, de la fuerza de 100 caballos o ferrocarriles, que transportan en un soplo millares de muchachos de la sima de la ignorancia al pináculo del saber"98.

En el momento de mayor impulso a la escuela lancasteriana, ésta no logró superar el establecimiento de las escuelas por el método antiguo, las cuales

95 Ibíd., p. 198.

4* Rodriguez, S., Consejos de un amigo dados al Colegio de Latacunga: 1850, en Obras Completas, Caracas, Editorial Arte, 1975, V. 1, p. 77.

97 Rodríguez S., Luces y virtudes sociales: 1840, en Obras Completas, Caracas, Editorial Arte, 1975. V. 2, p. 187.

98 Rodriguez S., Extracto sucinto sobre mi obra sobre la educación republicana: 1849, en Obras Completas, Caracas, Editorial Arte', 1975. V. 1, p. 247. 
se mantuvieron básicamente por el apoyo de los curas párrocos y los padres de familia, sobre todo en los territorios más apartados.

Es muy posible que en la adopción del método lancasteriano en Colombia éste hubiese sido modificado, ya que en el Manual de Enseñanza Mutua solo se contemplaba el leer, escribir y contar, pero los certámenes públicos realizados en el país dan cuenta, es de la enseñanza de temas diversos en la escuela elemental partiendo de los estipulado tanto en la legislación de 1821 como en el plan de estudios de 1826, los que se contemplaba la enseñanza de la religión, la gramática, la ortografía, la aritmética, la geometría, los derechos y deberes del hombre y del ciudadano, la urbanidad, la buena crianza y èl catecismo político constitucional, entre otros.

\section{CONCLUSIONES}

La realidad social de la Gran Colombia era precaria: escasez de escuelas, ausencia de población instruidà que pudiera desempeñarse como maestro de escuela pública, desconocimiento de métodos modernos, ausencia de libros e insuficiencia de recursos oficiales para sacar adelante el proyecto educativo republicano. Esta situación fue sorteada de dos maneras: convocando a toda la nación para que coadyuvara en la obra de la educación, donando recursos, ofreciendo espacios para la apertura de escuelas, pagando maestros, traduciendo libros, entre otros, y adoptando el método pedagógico que permitiera avanzar la educación partiendo de las condiciones concretas del país. El método que mejor respondía a esta condición concreta fue el de enseñanza mutua o lancasteriano.

El proyecto pedagógico republicano adoptó el sistema de la enseñanza mutua como mecanismo que permitiría la unificación del método. Para su implementación se adoptó el reglamento de las escuelas británicas, las cuales habían popularizado el método lancasteriano desde comienzos del siglo xIx. El gobierno colombiano dispuso todas las condiciones posibles para establecerlo en Colombia fomentando la apertura de escuelas, formando los maestros, adecuando los espacios físicos de las escuelas y adquiriendo materiales didácticos que el método requería, importándolos desde el exterior. Pero esta operatividad para la implementación del método constituyó 
el primer obstáculo para lograr que se generalizara en el país, además de lo costoso que resultaba y del tiempo que se invertía en una serie de trámites burocráticos. En un país tan pobre como Cólombia, resultába difícil sostener un método pedagógico que no contaba con las materias primas básicas para su implementación, como el hecho de tener que traer pizarras y lápices desde Nueva York porque en el país no se producían.,

En la difusión del método lancasteriano jugaron un papel muy importante las diferentes sociedades de apoyo a la instrucción que se establecieron en el país a partir de 1825 , dado que ellas aportaron'recursos;valiosos para la apertura de escuelas, el pago de los maestros, la traducción de los manuales y la entrega de libros y premios para los niños.

Así como lás :sociedades contribuyeron en la difusión del método y: en el sostén a la instrucción elemental, los curas párrocos, junto con los padres de familia, se constituyeron en los principáles actores sociales que impulsáron y apoyaron el establecimiento de la educación pública republicana.

El método lancasteriano se adoptó desde los inicios de la República por considerar que para su desarrollo sé requerían menos escuelas, menos maestros y menos salarios. El objetivo de unificar el método no llegó a cumplirse, porque no llegaron a instalarse el número de escuelas suficientes en todo el país y no todos los maestros se formaron en el método; lo que contribuyó a qué se continuara utilizando con mayor frecuencia el método antiguo.

En la permanencia del método antiguo influyeron además otras circunstancias: era más fácil porque củalquier persona que medianamente supiera leer, escribir y contar podría laborar como maestro siempre y cuando acreditara su condición moral y religiosa; más barato porque en general ganảaban menor salario, y porque no se requería mayor inversión para la apertura de la escuela, dado que no era necesario ningún móbiliario especial, ni materiales específicos ni demasiados libros, ya que bastaba con algunos catecismos que eran, relativamente, de fácil y más rápida adquisición porque los trámites para la apertura de la escuela solo dependían de quue existiesè là voluntàd del cura párroco o de los padres de familia de apoyar económicamente al maestro con el salario para quéesta se abriera: Estas condiciones contribuyeron en la permanencia del método antiguo en las escuelas. 


\section{BIBLIOGRAFÍA}

AGN. Sección: República. Fondo: Ministerio de Instrucción pública. T. $106,107,108$.

Amunategui Solor, D., El sistema de Lancaster en Chile $y$ otros paises sudamericanos, Santiago de Chile, Imprenta de Cervantes, 1895.

Anónimo. Manual para el método de enseñar la costura en las escuelas lancasterianas de niñas de la República del Perú, adoptado del que sé usa en las escuelas elementales de Inglaterra, Lima, Imprenta de la in'strucción primaria, 1827.

Bushnell, D., El Régimen de Santander en la Gran Colombia., Bogotá, Tercer Mundo Editores y Universidad Nacional de Colombia, 1966.

Correo del Magdalena, Cartagena, 22 de septiembre de 1825, n.19.

Correo de Bogotá, 23 de mayo de 1822, nº 147.

El Conductor, Bogotá; 6 de febrero de 1827, $\mathrm{n}^{\circ} .2$.

El Conductor, Bogotá; 27 de marzo de 1827, $\mathrm{n}^{\circ} .16$.

El Conductor, Bogotá; 19 de julio de $1827, \mathrm{n}^{\circ}, 151$.

El Constitucional, Bogotá; 19 de julio de 1827, $\mathrm{n}^{\circ} .151$.

El Eco de Antioquia, 15 de diciembre de 1822, $\mathrm{n}^{\circ} .30$.

El Eco de Antioquia, 26 de enero de 1823, $\mathrm{n}^{\circ} .36$.

El Fósforo de Popayán, Popayán, 13 de febrero de 1823, nº 3.

Gaceta de Colombia, Bogotá, 16 de septiembre de 1827, nº 309.

Gaceta de Colombia. Bogotá, 15 de septiembre de 1822, nº 48.

Gaceta de Cartagena, Cartagena, 7 de enero de 1826. $\mathrm{n}^{\circ} .229$. 
Gaceta de Cartagena, Cartagena, del 25 de septiembre de 1824, $\mathrm{n}^{\circ} .163$.

Gaceta de la Nueva Granada, nº 110,3 de noviembre de 1833.

Gaceta de la nueva granada, $\mathrm{n}^{\circ} .135,27$ dè abril de 1834 .

Grisanti, A. Resumen histórico de la instrucción pública en Venezuela, Bogota, Editorial Iquema, 2a ed., 1950.

Lancaster, J., Origen y progresos del nuevo sistema de enseñanza mutua del señor Lancaster, Londres, s.f., p. 1.

, Manual del Sistema de Enseñanza Mutua aplicado a las escuelas primarias. Bogotá, S.S. Fox, 1826.

Ley 15 del 6 de agosto de 1821, sobre el establecimiento de escuelas de - primeras letras para los niños de ambos sexos. En: codificación nacional, Imprenta nacional, 1924, tomo 1, p. 29.

Rodríguez, S., Consejos de un amigo dados al colegio de Latacunga: 1850. Obras completas, Caracas: Editorial Arte, 1975, V. 1.

, Extracto sucinto sobre mi obra sobre la educación republicana: 1849. Obras completas, Caracas: Editorial Arte, 1975, V. 1.

, Luces y virtudes sociales: 1840, Obras completas, Caracas: Editorial Arte, 1975, V. 2.

Safford, F., El ideal de lo práctico, Bogotá, Universidad Nacional de Colombia, Áncora Editores, 1989.

Salcedo Bastardo J. L., El primer deber: con el acervo documental de Bolivar sobre educación. Caracas, Ediciones de la Universidad Simón Bolívar, 1973. 